\title{
Article \\ Entropy Method of Road Safety Management: Case Study of the Russian Federation
}

\author{
Artur I. Petrov (D)
}

Citation: Petrov, A.I. Entropy

Method of Road Safety Management: Case Study of the Russian Federation. Entropy 2022, 24, 177. https:// doi.org/10.3390/e24020177

Academic Editor: Pavel Sevastjanov

Received: 8 December 2021

Accepted: 21 January 2022

Published: 25 January 2022

Publisher's Note: MDPI stays neutral with regard to jurisdictional claims in published maps and institutional affiliations.

Copyright: (C) 2022 by the author. Licensee MDPI, Basel, Switzerland. This article is an open access article distributed under the terms and conditions of the Creative Commons Attribution (CC BY) license (https:// creativecommons.org/licenses/by/ $4.0 /)$.
Department of Road Transport Operation, The Institute of Transport, Industrial University of Tyumen, 625027 Tyumen, Russia; ArtIgPetrov@yandex.ru; Tel.: +7-(912)-079-19-91

\begin{abstract}
Within the framework of this paper, the author's entropy method of road safety management in large-sized systems is considered. The road safety management system in the Russian Federation, the largest country in the world, was selected for this case study. The purpose of the article is to present the opportunities and methodology of the use of quantitative assessments of the orderliness of the road accident rate formation process in regional transport systems for road safety management. Orderliness, in other words, systemic anti-chaos, can be quantified using the C. Shannon informational entropy $H$. The article consists of the results of the issue's state analysis; methodology of assessment of the orderliness of the road accident rate formation process based on the using of the cause-and-effect chain; entropic method of the road safety management in large-scale systems, in particular, the algorithm of management of regional road safety in Russia taking into account the level of its entropic orderliness; and examples of the quantitative evaluation of the orderliness of regional road safety provision systems in Russia. The key results of the research are spatio-temporal patterns of the change of the orderliness of the road safety provision systems in the Russian Federation in 2004-2020. Based on the results, conclusions and recommendations about the practical application of the entropic method of road safety management in large federal states with complex administrative structures were formulated. These results give an idea of the possibilities of the usage of entropic approaches in road safety management to assess the orderliness of the regional transport systems and the advantages of the entropic method over other managerial methods.
\end{abstract}

Keywords: entropy; quantitative assessment; Shannon's relative entropy; system orderliness; road safety management; Russian Federation

\section{Introduction}

Socio-technical systems are characterized by the highest level of complexity. A huge number of system elements and a great variety of connections between them determine a high level of the probability of chaos in such systems. That is why many regulatory documents and technical and technological procedures are being developed to manage their functioning. Their primary goal is to regulate and control the implementation of individual actions by the process participants in order to reduce the number of possible process outcomes. In addition, it is important to control the quality implementation of the requirements of these regulations. The ultimate goal of management is to transfer the controlled system to the desired, targeted, more or less unambiguous, planned state, which means reducing the level of chaos in the system.

The main purpose of road traffic safety systems is to reduce the likelihood of incidents (in the form of road traffic accidents) in the functioning of the transport system. Analytical work with statistical data characterizing the road accident rate does not allow us to fully understand the mechanisms of its formation. Only the use of a deeper entropy analysis can help in substantive assessment of what is happening on a large scale, for example, regional road safety systems. 
Over the last 125 years of active motorization, in the field of road safety, five paradigms have successively replaced one another-approaches, practices, and knowledge systems generally recognized by the entire scientific community [1,2]. However, the process of rebuilding road safety systems is extremely heterogeneous in terms of space and time. Even in the regions of one country, very different road safety practices related to different paradigms simultaneously coexist. This largely depends on the characteristics of the socioeconomic development of the regions [3]. To a greater extent, this is typical for large-size countries. Russia, with its 17.5 million $\mathrm{km}^{2}$ of land and with more than 190 peoples and nationalities inhabiting it, is a vivid example of a state with a wide variety of public administration practices.

According to N.V. Zubarevich [4]: "today there exist four different versions of Russia at the same time-metropolitan Russia, Russia of large cities, Russia of small and mediumsized cities, and rural Russia", each of which is fundamentally different not only in the socio-economic standard of living but also in people's way of life, mentality, and habits. At the everyday level, this is manifested in a variety of behavioral practices, including on the road when driving a vehicle $[5,6]$.

At the state level, the issues of ensuring road traffic safety in Russia have received great attention since 2006. It was then that the first (2006-2012) and the second (2013-2020) [7] federal target programs on road safety were adopted and began to be implemented. Starting from 2018, road safety management processes in Russia are based on the targets of the Road Safety Strategy in the Russian Federation for 2018-2024 [8].

According to this document, by 2024, the level of Human Risk (HR) (one of the main status indicators of road safety) in Russia should be reduced to 4 road deaths/100 thousand people. In 2020, Human Risk in Russia was HR = 11.01 road deaths / 100 thousand people [9], which means that within 4 years (2021-2024), it would be necessary to reduce the road death rate as the final outcome of road traffic accidents in Russia by 2.75 times or by $175 \%$.

Recall that Human Risk (HR) is calculated according to (1) [1]:

$$
H R=\frac{N_{R A \text { deaths }}}{(P / 100,000)},
$$

where

$N_{R A \text { deaths }}$ - the number of deaths in road accidents, people;

$P$-population, people;

100,000 - conversion factor.

Analysis shows that this is hardly possible [10,11].

Examples of other world-leading countries in the field of road safety indicate that it took them 10-36 years to solve this problem (Table 1) [12,13]. Initially, Russia planned to solve this problem within 5 years (2020-2024). However, it quickly became clear that the long journey of other countries to $H R=4$ road deaths $/ 100$ thousand people is quite justified.

In 2020, the country's leadership realized that the task could not be solved by 2024 . In this regard, by the Decree of the President of the Russian Federation No. 474 of 21 July 2020, the deadline for achieving the goal in $H R=4$ road deaths $/ 100$ thousand people was shifted from 2024 to 2030 [14].

Note that having already reached the level of $H R=4$ road deaths $/ 100$ thousand people, Germany, Spain, and the Netherlands have remained at this level for almost a decade and have not yet been able to improve the situation in the field of road safety. Maybe this is due to the internal policies of these countries, which are quite liberal and do not overly restrict the freedoms of citizens. Perhaps, without a total infringement on civil liberties, the task of a significant increase in the road safety level cannot be solved. In any case, this is evidenced by the analysis of the data in Table 1. International practices do not have examples of such rates of Human Risk reduction that were set for Russia by the Road Safety Strategy in the Russian Federation (2018-2024). 
Table 1. Duration of the period of reduction of Human Risk (HR) from level 11 to level 4 road deaths/100 thousand people $[12,13]$.

\begin{tabular}{ccccc}
\hline Country & $\begin{array}{c}\text { Duration } \\
\text { of the Period } \\
\text { of HR Reduction } \\
\text { from 11 to } 4 \\
\text { RA Fatalities } \\
\text { /100,000 People }\end{array}$ & $\begin{array}{c}\text { Year } \\
\text { of Reaching } \\
\text { the HR Level } \\
\text { of 11 RA } \\
\text { Fatalities } \\
\text { /100,000 People }\end{array}$ & $\begin{array}{c}\text { Year } \\
\text { of Reaching } \\
\text { the HR Level } \\
\text { of 4 RA } \\
\text { Fatalities } \\
\text { /100,000 People }\end{array}$ & $\begin{array}{c}\text { Current } \\
\text { (2018) } \\
\text { HR Level, } \\
\text { RA Fatalities } \\
\text { /100,000 People }\end{array}$ \\
\hline Norway & 30 & 1978 & 2008 & 2.0 \\
Switzerland & 20 & 1991 & 2011 & 2.7 \\
Great Britain & 32 & 1977 & 2009 & 2.8 \\
Ireland & 12 & 2000 & 2012 & 2.9 \\
Denmark & 19 & 1992 & 2011 & 3.0 \\
Sweden & 29 & 1980 & 2009 & 3.2 \\
Japan & 36 & 1978 & 2014 & 3.3 \\
Estonia & 12 & 2005 & 2017 & 3.6 \\
Netherlands & 25 & 1984 & 2009 & 3.9 \\
Spain & 10 & 2003 & 2013 & 3.9 \\
Germany & 27 & 1989 & 2016 & 4.0 \\
\hline
\end{tabular}

Does Russia have a chance to greatly accelerate the course of history and take advantage of the already existing developments of foreign authors in order to realize extremely ambitious goals? By implementing what solutions can this be achieved? What is the specificity of road safety formation in different regions of the Russian Federation? Can entropy analysis help in understanding the processes of road accident rate formation? An attempt to answer these questions was made by the author within the framework of this paper.

\section{Analysis of the Issue-Theoretical Foundations}

\subsection{Generally Accepted Road Safety Management Methods}

The global goal of road safety management is to minimize the number of fatalities in road accidents down to zero. In fact, we must talk about management as a search for ways to reduce the likelihood of the formation of emergency situations in the transport system, i.e., about reducing the level of systemic chaos through the implementation of managerial decisions aimed at improving the orderliness of the transport system or at least the part of it that specializes in road safety. The Swedish program Vision Zero [15], adopted by the Swedish Parliament in October 1997, declares the following main approaches to achieving this goal (Figure 1): improving the road transport infrastructure; controlling the speed limit; improving vehicle safety; working with the mentality of people; and the formation of safe stereotypes of behavior among road users.

\section{SAFE TRAVEL FOR ALL}

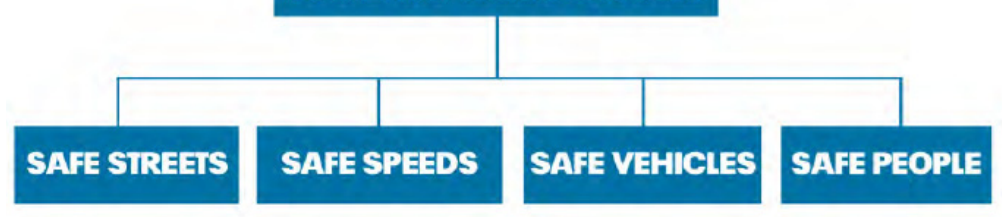

Figure 1. Four approaches to achieving the goal of zero road deaths (Vision Zero) [15]. 
The main methods of road safety management correspond to the above basic approaches. It is often organizationally difficult to implement all approaches in practice at the same time due to a shortage of resources of all types. Therefore, most often, we can see the choice of only one approach as a priority [16]. For example, in Russia, in recent years (2019-2021), an approach to improve the road transport infrastructure is the method of choice [17]. At the physical level, this is expressed not only in improving the quality of highways $[18,19]$ but also in complicating traffic flow regulation $[20,21]$.

We know [22-24] that a much more effective method for increasing road safety is changing the stereotypes of typical behavior of road users. The analysis $[25,26]$ shows that statistically significant effects of changes in people's behavior are formed under conditions of creating an atmosphere of reward for the required behavioral imperative and, conversely, punishment in case of violations of the prescribed rules. It has been statistically proven that traffic rules are observed to the fullest extent possible in countries with the highest rates of fines for their violation [27]. However, not only fines affect the behavior of road users but also the peculiarities of the national mentality [28], which has been developing over the centuries [29]. An analysis of the research results [30,31] showed that the degree of influence of such an approach to improving road safety as control over the speed limit with subsequent punishment for violations varies in different countries [30] and even in the regions of one country [31].

2.2. Heterogeneity of the Conditions for the Functioning of Russian Regional Transport Systems as a Challenge to the Quality Road Safety Management on the Part of Federal Bodies

Russia is a federal state governed from a single center on the basis of a unified legislation. The Russian Federation unites 85 subjects ( 82 territories and 3 cities of federal subordination) (Figure 2). The constituent entities of the Russian Federation are united in eight Federal Districts: Central, Northwestern, Southern, North Caucasian, Volga, Ural, Siberian, and Far Eastern. The best climate, maximum population density, and, accordingly, better living conditions are typical for the Central and Southern Federal Districts. The Ural Federal Districts, Siberian Federal Districts, and Far Eastern Federal Districts encompass territories with a harsh climate; low population density and low degree of socio-economic development of the territories are quite consistent with very harsh living conditions.

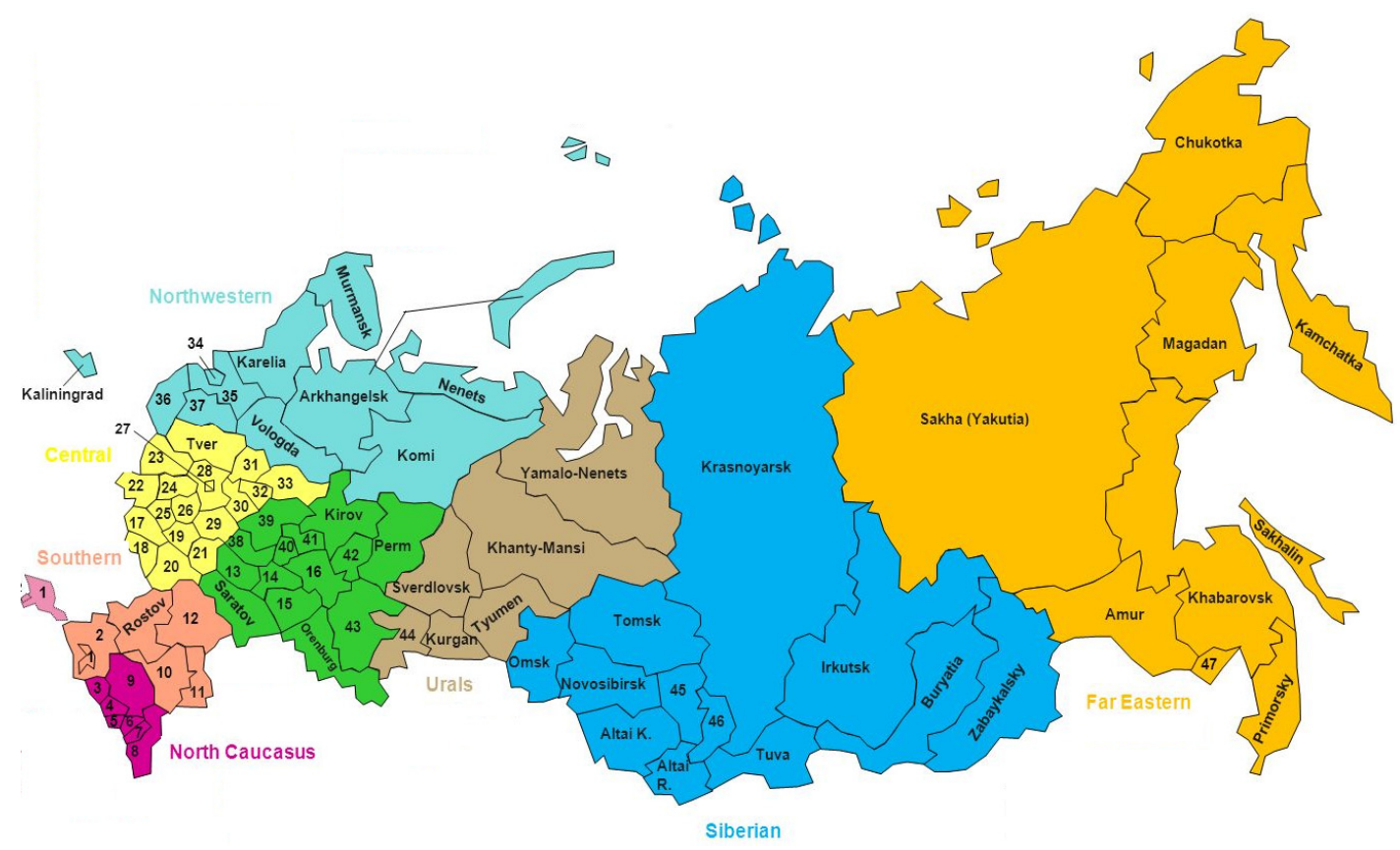

Figure 2. Administrative division of the Russian Federation into 8 Federal Districts, (highlighted on the map in different colors) and 85 subjects of the Federation (regions). 
The transport system of a country is a set of regional transport systems which in turn unite regional subsystems of the road transport infrastructure, vehicle fleet, regulation of the transport process, ensuring road safety, and many other subsystems that support the transport process. The development of regional transport systems in Russia is very heterogeneous-from a level comparable to EU countries (for example, the Moscow region) to a level close to that of African countries (for example, the Republic of Tyva).

In the Russian Federation, as of 31 December 2020, there were 58,993 thousand vehicles in the road network with a total length of 1553.6 thousand $\mathrm{km}$. During operation in 2020, 145,073 road accidents occurred in the Russian Federation [32] (in Russia, the concept of road traffic accidents applies to cases with the dead and injured; other incidents on the road-with only material damage-are not included in the official statistics).

Within the territory of the country, road accidents are distributed extremely heterogeneously, which largely depends on the density of the population, its socio-economic situation, the degree of development of the road transport infrastructure, the quality of the vehicle fleet, and many other factors. This heterogeneity can be easily identified even in case of neighboring regions, for example, the Moscow and Vladimir regions (Figure 3).

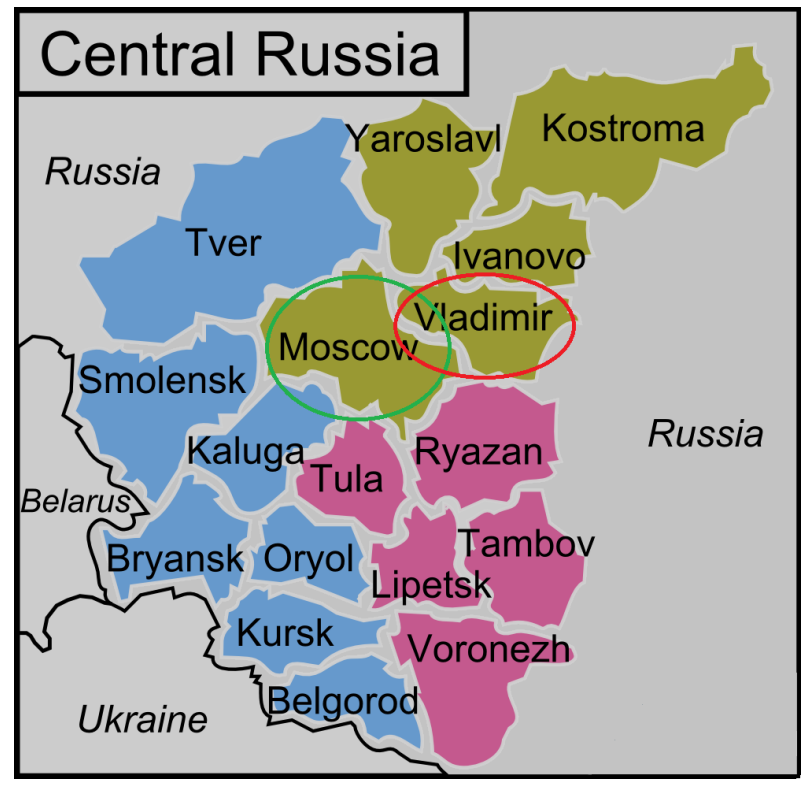

(a)

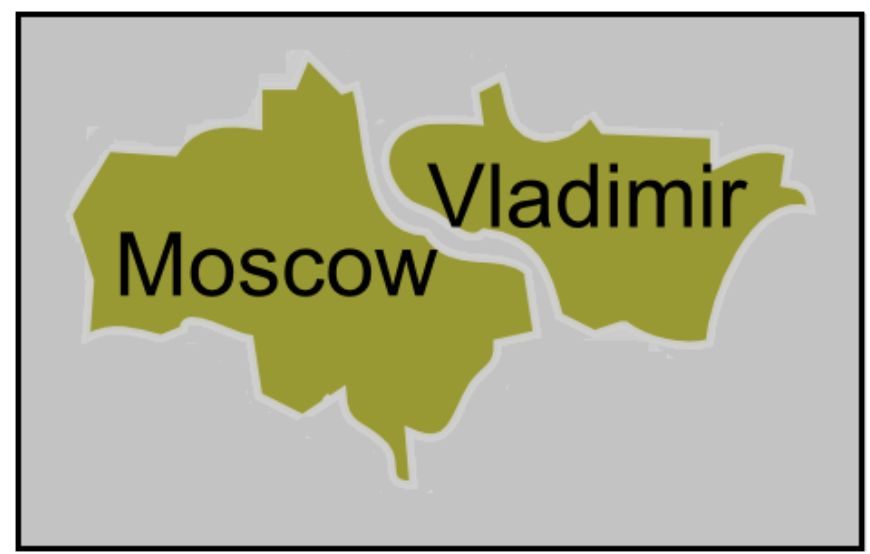

(b)

Figure 3. Geographical location of the compared Russian regions. (a) Central Federal District of the Russian Federation; (b) Geographically adjacent Moscow and Vladimir regions.

In the adjacent Moscow and Vladimir regions, both the living conditions of the population [33] and the characteristics of road accident rates $[9,32]$ are qualitatively different (Table 2).

There are many similar examples for the Russian Federation-the Republic of Tatarstan and the Republic of Mordovia, Tyumen and Kurgan regions, etc. Among the 85 constituent entities of the Russian Federation, there are virtually no identical regions comparable in terms of the level of socio-economic development.

As a result, different budgetary provision and different levels of quality of life of the population have formed in the regions of the country. This diversity is also manifested in the field of road safety (Table 2).

Perhaps, it can be argued that the heterogeneity of the conditions for the functioning of regional transport systems is a serious challenge to the quality road safety management on the part of federal bodies.

At the same time, it becomes clear that federal bodies have few tools for assessing the qualitative state of the actual level of development of regional road safety systems. This 
toolkit for road safety management (in the form of an approach or a method) is extremely important precisely for large and complex countries such as Russia.

Table 2. Actual socio-economic living conditions of the population and the level of road accident rate in the neighboring regions of Russia in 2019 [9,32,33].

\begin{tabular}{|c|c|c|c|c|c|c|c|}
\hline \multirow[b]{2}{*}{$\begin{array}{l}\text { Geographically } \\
\text { Adjacent Regions } \\
\text { of the Russian } \\
\text { Federation }\end{array}$} & \multicolumn{4}{|c|}{$\begin{array}{l}\text { Characteristics of the Socio-Economic } \\
\text { Development of Regions [33] }\end{array}$} & \multicolumn{3}{|c|}{$\begin{array}{l}\text { Road Accident Rate } \\
\text { Characteristics }[9,32]\end{array}$} \\
\hline & 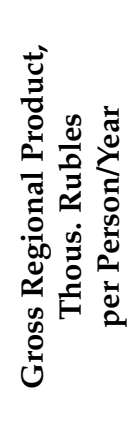 & 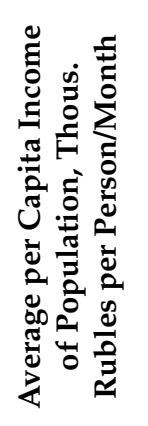 & 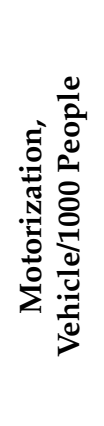 & 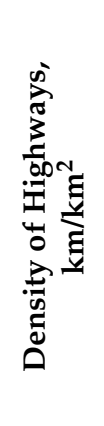 & 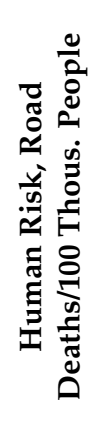 & 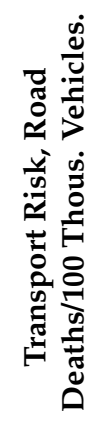 & 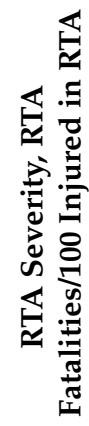 \\
\hline Vladimir region & 394.6 & 25.3 & 366 & 0.522 & 19.08 & 52.12 & 7.69 \\
\hline Moscow region & 670.8 & 47.2 & 416 & 0.972 & 12.50 & 30.01 & 11.44 \\
\hline
\end{tabular}

\subsection{The Problem of the Correct Choice of Indicators of Quality Road Safety Management}

The problem of effective road safety management within a large country such as the Russian Federation is the absence of a clear methodology and a set of correct indicators for assessing the quality of such management. Today, the goal of road safety management is clear-to achieve the planned level of $H R=4$ road deaths $/ 100$ thousand people by 2030 in the entire country. However, it is unclear how to organize the processes of achieving this goal for numerous regions in Russia ( 85 in total). The current approach is to use three absolute indicators to assess the road safety state in the regions of the country-the annual road accident number, the annual number of injured and dead in road accidents, and one relative indicator-the road accident severity, as well as a comparison of the current values of these characteristics with their values in previous time periods. This approach is not only ineffective but also methodologically incorrect. Analytical work on a comparative assessment of the road safety state in road transport systems varying in area, population, and the degree of development cannot and should not be carried out on the basis of the analysis of absolute indicators. This is incorrect [34], and experts are well aware of this. However, they have no other tools, although they are very interested in obtaining them.

\subsection{Substantiation of the Choice for Characterizing the Quality of Road Safety Management by Information Entropy}

In its modern interpretation, the high quality of process management or management of the functioning of complex systems is characterized by a low level of chaos of processes and a high probability of finding a system at a certain, given state [35]. The probability of finding a system at a given state is a function of information entropy [36].

The concept of entropy has a complex history. It was first introduced by R. Clausius in thermodynamics in 1865 to determine the measure of irreversible dissipation of energy, the measure of deviation of a real process from an ideal one [37]. Over the next one hundred and fifty years, the concept of entropy has become widely used in various scientific fields. As M.M. Kostic points out in [38]: «Entropy is the most used and often abused concept in science, but also in philosophy and society. Further confusions are produced by some attempts to generalize entropy with similar but not the same concepts in other disciplines ... Von Neumann once remarked that "whoever uses the term «entropy» in a discussion always wins since no one knows what entropy really is, so in a debate one always has the advantage". The historian of science and mathematician, Truesdell, explains 
in his essay of Method and Taste in Natural Philosophy: "Heads have split for a century trying to define entropy in terms of other things"».

An in-depth analysis carried out by Portuguese authors [39] on entropy helped not only to formalize the history of the development of the concept of "entropy" but also to construct the so-called Entropy Universe (Figure 4).

The central place in it is occupied by Shannon entropy or information entropy [40]. It is information entropy that today dominates among other entropies. Statistical analysis by the team of authors M. Ribeiro et al. [39] showed that, in total, articles published in the Scopus peer-reviewed journals mention Shannon information entropy 34,751 times, which is about $49.2 \%$ of the total number of mentions of 40 other types of entropy (70,495 in total). Perhaps, the same conclusion can be made by visually assessing the central localization of Shannon entropy in the diagram in Figure 4 and the number of logical connections between Shannon entropy with other types of entropy.

Information entropy $H$, or Shannon entropy, characterizes the probability of a certain macroscopic state to be performed. The low level of entropy $H$ means that there are far fewer ways to obtain a given macro-state from its microscopic ingredients. Such configurations are difficult to find, unusual, carefully organized, and rare.

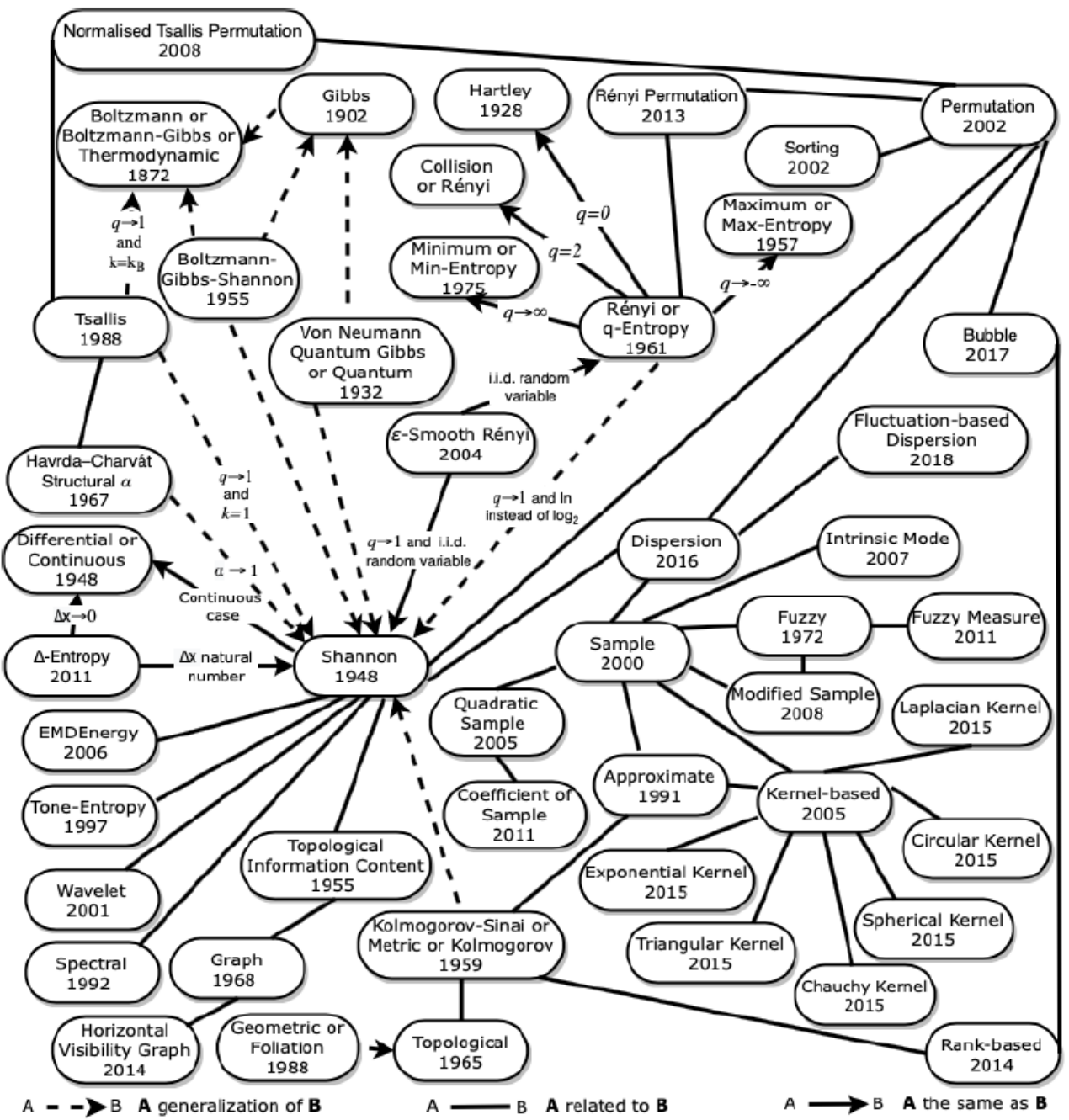

Figure 4. The Entropy Universe [39].

2.5. Information Entropy of a System as a Basis for Analyzing the Quality of Road Safety Management: Orderliness as a Systemic Property

As applied to transport systems, information entropy $H$ identifies the probability of a transport system being in a chaotic state, i.e., a condition for which the safety level is low. It 
is logical that under conditions of simultaneous interaction of a multitude of vehicles (their number depends on the scale of the system being evaluated), the probability of their safe interconnection in the process of movement is relatively small. However, this probability of a safe state of the transport system can be increased through the use of various instruments for regulating its functioning. Striking examples of such regulation are traffic rules, traffic light control systems for traffic flows, differentiation of traffic flows in space, and many other important methods of organizing traffic. In general, traffic management is a tool for reducing the information entropy of a transport system and bringing it into a state of order, i.e., increasing its orderliness. However, a person (driver or pedestrian) uses these tools and does not always follow the recommendations of restrictions and systems that regulate traffic processes. As a result, there is an increase in systemic chaos and disorganization of those processes that must be ordered.

The extent to which the problem of improving the system orderliness is solved in practice can ultimately be assessed by means of Shannon information entropy [40]. With regard to the quality of road safety management, Shannon entropy identifies the level of orderliness of the road safety system. The lower the value of information entropy $H$, the higher the orderliness of the system. The classical Shannon Formula (2) for the case of assessing the orderliness of the road safety system takes on the following meaning:

$$
H=-\sum_{i=1}^{n} w_{i} \cdot \ln w_{i}
$$

where

$n$-the number of transfer links in the formation of a road accident rate (in our case $n=4$ ) and $\omega_{i}$-the coefficients of significance or "weight" of each link in the formation of a road accident rate that meet the rate setting condition $\sum_{i=1}^{n} \omega_{i}=1$.

The number of links studied in terms of assessing the orderliness of the management process can be different and depend on the availability of statistics or on the formulation of the problem.

For the convenience of using this tool in order to conveniently compare the assessment of the quality of road safety management in different regions of the country, it is perhaps better to use the relative entropy indicator $H_{n}(3)$ :

$$
H_{n}=H / H_{\max }=H / \ln (n)
$$

The theoretical range of values of the relative entropy $H_{n}$ RSS of road safety systems $H_{n R S S}=[0 ; 1]$, however, in practice, $H_{n R S S}$ for the four-link process of road accident rate formation is most often in the range $H_{n} R S S=[0.65 ; 0.85]$ [41]. Lower values of the relative entropy $H_{n}$ RSS indicate a relatively high quality of road safety management and vice versa [41].

\section{Methodology for Assessing the Orderliness of the Process of the Road Accident Rate Formation}

Generally speaking, the target function of road safety management is to minimize all types of damage from road accidents, primarily direct damage associated with the death and injury of people in traffic accidents. In general, socio-economic damage in different countries of the world varies in the range from $0.8 \%$ to $4 \%$ of Gross Domestic Product (GDP) [42,43], and this value is determined by two main factors-the general level of road safety in the country and the level of the average cost of living of the citizens of this country [44]. These two aspects are interconnected by means of risk homeostasis, which is familiar to and accepted by the citizens of the country [45]. G.J.S. Wilde [45] believes that it is risk homeostasis that is the primary basis for understanding how the process of road accident rate is formed. 
Without touching on the topic of assessing damage from road accidents in detail, we point out that many works are devoted to this topic [46-48]. Two aspects are important here: first, understanding that damage from road death is the highest in value and significantly exceeds material damage; and second, the ratio between the size of the vehicle fleet in the country, the number of road accidents, the number of victims in road accidents, and the proportion of fatalities among those injured in road accidents in different countries varies greatly. The same difference is typical for different regions of the same country and is determined by many circumstances of a socio-economic nature (Table 2).

Specifying the formulation of the target function of road safety management, we note the following: the general target function of road safety management at the federal level in large complex countries is to minimize the relative entropy $H_{n}$ RSS of the road safety formation process by maximizing the overall utility (positive $Q$ ) of the road accident rate formation process.

From a general philosophical point of view, it is impossible to look for a positive in road accidents, but let us consider the positive $Q$ as a measure of the amount of information or a derivative of the entropy of the process under study.

Formalization of the concept of "Road accident rate" in terms of the process description leads us to a cause-effect 4 -link chain «Population $(P)$-The number of vehicles $\left(N_{V h}\right)$-The number of road accidents $\left(N_{R A}\right)$-The number of victims $\left(N_{V}\right)$-The number of deaths $\left(N_{D}\right)$ » [49] (Figure 5).

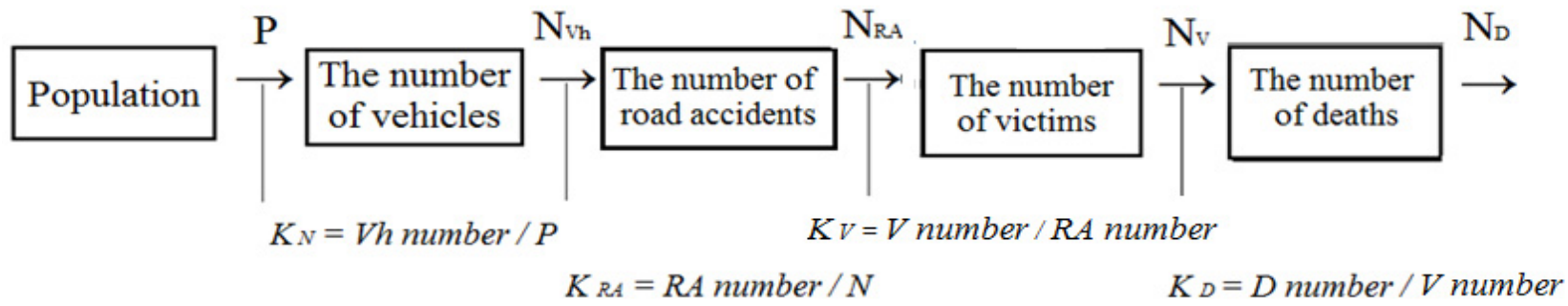

Figure 5. The cause-effect chain of road accident rate formation [49].

In this case (Figure 5), the process of road accident rate formation is considered as a set of four process links between the five main blocks of the process.

The road accident rate as a process can have many options. The distinction of the options is determined by the numerical values of the transition coefficients $K_{i}$ between the blocks of the cause-effect chain of the road accident formation process $\left(K_{N} ; K_{R A} ; K_{V} ; K_{D}\right)$. The positive of a separate link in the process $Q i$ is associated with the transition coefficient $K_{i}$ by means of the relation (4):

$$
Q_{i}=\ln \left(1 / K_{i}\right) \text { if } K_{i}<1 \text { or } Q_{i}=\ln \left(K_{i}\right) \text { if } K_{i}>1 .
$$

In general, the overall utility or positive of the process is identified as (5):

$$
\begin{gathered}
Q=\ln \left(1 / K_{H R}\right)=\ln \left(1 / K_{N}\right)+\ln \left(1 / K_{R A}\right)+\ln \left(K_{V}\right)+\ln \left(1 / K_{D}\right)=Q_{N}+Q_{R A}+Q_{V}+Q_{D}, \\
\text { where }
\end{gathered}
$$

$K_{H R}$-the end-to-end path transmission factor $K_{H R}=D$ number $/ P$;

$Q_{N}=\ln \left(1 / K_{N}\right)$-the share of the process positive attributed to the link "the number of vehicles";

$Q_{R A}=\ln \left(1 / K_{R A}\right)$ 一the share of the process positive attributed to the link "the number of road accidents";

$Q_{D}=\ln \left(K_{v}\right)$-the share of the process positive attributed to the link "the number of victims"; $Q_{D}=\ln \left(1 / K_{D}\right)$-share of the process positive attributed to the link "the number of deaths".

The use of the coefficient $K_{H R}$ in the model (4), i.e., the result of the ratio "The number of deaths $\left(N_{D}\right) /$ Population $(P)^{\prime \prime}$ is predetermined by the physical meaning of this coefficient. 
$K_{H R}$ is a version of Human Risk (HR), proposed back in 1949 by R. Smeed [50,51], but in a slightly different dimension. Note that the higher the value of the positive, the higher the quality of the entire system of organization and management of road safety.

An important step in the methodology is to determine the structure of the weight coefficients $w_{i}$ for assessing the positive contribution $Q$ of various links in the chain "Population $(P)-<\ldots>$-The number of deaths $\left(N_{D}\right)^{\prime \prime}$. The calculated weight values of the positive $w_{R A}$, $w_{V}$, and $w_{D}$ allows for solving the main problem of entropy analysis-assessing the degree of influence of various blocks (links) of the chain "Population $(P)-<\ldots>$-The number of deaths $\left(N_{D}\right)$ " in the formation of the final accident rate.

The share of each link $w_{i}[52]$ of the cause-effect chain of road accident rate formation in the overall balance as (6):

$$
w_{i}=\frac{Q_{i}}{\sum_{i=1}^{4} Q_{i}}=\frac{Q_{i}}{\ln \left(1 / K_{N}\right)+\ln \left(1 / K_{R A}\right)+\ln \left(K_{V}\right)+\ln \left(1 / K_{D}\right)}
$$

The obtained estimates of the "weights" $w_{i}$ or the values of individual process links in the overall process are the starting material for the structural analysis of the process under study. Thus, relative entropy $H_{n}$ characterizes, first of all, the structure of the entire process of the road accident rate formation, rather than the ratio of the final result of the process-«The number of deaths $\left(N_{D}\right)$ by Population $(P) »$. Quantitative estimates of the "weights" $w_{i}$ of the process links are basic data for determining the entropy characteristics according to Formulas (2) and (3).

The relative entropy $H_{n}$ RSS of the road accident rate formation process is a characteristic of the system orderliness and allows one to objectively judge the general situation in the field of road safety for the local system. Quantitative estimates of the relative entropy $H_{n}$ RSS of the road accident rate formation process can be used both for spatial analysis of the state of road safety systems and for assessing the dynamics of the process in time.

To specify the methodology of the assessment of the orderliness of the road accident rate formation process, we present it in the view of the formulated stages. It should be noted that three examples of such staged assessment are given in Section 5 of this paper.

The methodology consists of the sequential implementation of the next operations:

1. The determination of the values of transitional coefficients $K_{i}$ between the blocks of the cause-and-effect chain of the road accident rate formation process $\left(K_{N} ; K_{R A} ;\right.$ $\left.K_{V} ; K_{D}\right)$.

2. The determination of the positive of the individual blocks of the road accident rate formation $Q_{i}$. Partial positives $Q_{i}$ of individual blocks of the studied process are connected with the transitional coefficient $K_{i}$ of the cause-and-effect chain by relation (3).

3. The determination of the common positive $Q$ by Formula (4).

4. The determination of the contribution $w_{i}$ of each block of the process $K_{i}$ into the common positive $Q$ by Formula (5). The physical meaning of $w_{i}$ is the determination of «weight» or «significance» of an individual block of the cause-and-effect chain in the total result.

5. The determination of the values $\left[\ln \left(w_{i}\right)\right]$.

6. The determination of the values $\left[w_{i} \cdot \ln \left(w_{i}\right)\right]$.

7. The calculation of the values of the $C$. Shannon informational entropy $H_{R S S}$ by the classic Formula (1).

8. The calculation of the values of the C. Shannon relative informational entropy $H_{n}$ RSS by Formula (2).

\section{The Proposed Entropy Method for Road Safety Management in Large-Scale Systems}

Road safety management in a large country such as the Russian Federation should be based on the use of a qualitative characteristic such as the relative entropy of the regional road safety system $H_{n}$ RSS . 
The main purpose of the entropy method is the differentiation of regions of a large country into groups with high, average, and low levels of orderliness of road safety systems. Depending on this, the programs for financing the goals of improving road safety are configured (Figure 6).

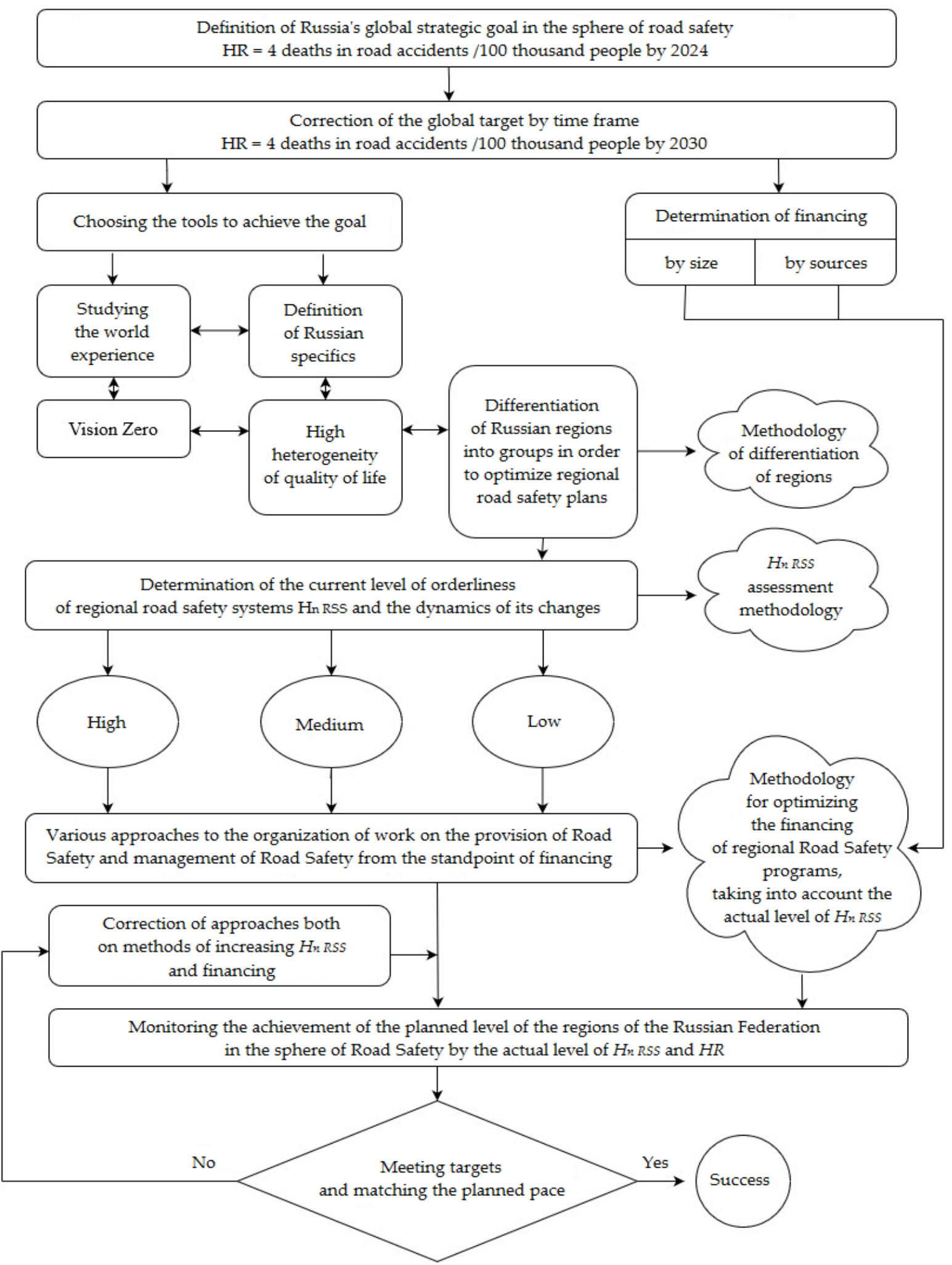

Figure 6. An algorithm for managing regional road safety in Russia, considering the level of its entropy orderliness. 
The algorithm for managing regional road safety in Russia considering the level of its entropy orderliness implies the use of three individual methodologies-the methodology for differentiating regions by groups, the methodology for assessing the relative entropy $H_{n}$ RSS of the regional road safety system, and the methodology for optimizing the financing of regional programs for road safety considering the actual level of $H_{n}$ RSS.

The detailing of these three methods is a task for future research that is not included in the scope of this article. In this regard, we leave it to the next stage of the corresponding research.

Next, we consider specific examples of a quantitative assessment of the orderliness of road safety systems.

\section{Examples of Quantitative Assessment of the Orderliness of the Federal Road Safety Management System in the Russian Federation and Some of Its Representative Regions}

Table 3 shows an example of calculating (year 2020) the relative entropy $H_{n}$ RSS of the all-Russian road safety system. We used the 2020 Statistical Book (Informational and analytical review) of the Research Center of the State Traffic Safety Inspectorate of the Russian Federation [9] as the source of data.

Table 3. Intermediate stages and the final result of calculating the relative entropy $H_{n} R S S$ of the road safety system of the Russian Federation (2020).

\begin{tabular}{|c|c|c|c|c|}
\hline $\begin{array}{l}\text { Population }(P) \\
\text { in the Russian } \\
\text { Federation } \\
(2020), \\
\text { People [9] }\end{array}$ & $\begin{array}{c}\text { Fleet } \\
\text { of Vehicles } \\
(V h) \\
(2020), \\
\text { Vehicles [9] }\end{array}$ & $\begin{array}{c}\text { Number } \\
\text { of Road } \\
\text { Accidents } \\
\text { (RA Number) } \\
\text { (2020), } \\
\text { Units [9] }\end{array}$ & $\begin{array}{c}\text { Number } \\
\text { of Victims } \\
\text { (V Number) } \\
\text { in Road } \\
\text { Accidents (2020), } \\
\text { People [9] }\end{array}$ & $\begin{array}{c}\text { Number } \\
\text { of Deaths } \\
\text { (D Number) } \\
\text { in Road } \\
\text { Accidents } \\
\text { (2020), People [9] }\end{array}$ \\
\hline $146,888,583$ & $58,992,696$ & 137,655 & 190,965 & 15,788 \\
\hline \multicolumn{5}{|c|}{ Values of coefficients of information transmission between links of the cause-effect chain } \\
\hline & & $K_{R A}$ & $K_{V}$ & $K_{D}$ \\
\hline 0.4 & & 0.0023 & 1.3873 & 0.0827 \\
\hline \multirow{2}{*}{\multicolumn{5}{|c|}{ Positive of a link in the cause-and-effect chain $Q_{i}=\ln \left(1 / K_{i}\right)$ if $K_{i}<1$ or $Q_{i}=\ln \left(K_{i}\right)$ if $K_{i}>1$}} \\
\hline & & & & \\
\hline \multicolumn{5}{|c|}{ Relative weight of positive of a corresponding link in the chain $w_{i}$} \\
\hline 0.0 & & 0.6189 & 0.0334 & 0.2546 \\
\hline \multicolumn{5}{|c|}{ Estimated value $\left[\ln \left(w_{i}\right)\right]$} \\
\hline-2. & & -0.4799 & -3.3984 & -1.3682 \\
\hline \multicolumn{5}{|c|}{ Estimated value $\left[w_{i} \cdot \ln \left(w_{i}\right)\right]$} \\
\hline$-c$ & & -0.2970 & -0.1136 & -0.3483 \\
\hline \multicolumn{5}{|c|}{ Estimated entropy value $H=-\sum_{i=1}^{n} w_{i} \cdot \ln w_{i}=0.980$} \\
\hline
\end{tabular}

Figure 7 shows the distribution of the numerical values of the relative entropy $H_{n}$ RSS of regional road safety systems in 85 constituent entities of the Russian Federation (2020).

The use of the methodology examples of calculating (2020) the relative entropy $H_{n}$ RSS of regional road safety systems for the best (Kamchatka Territory, Table 4) and the worst (Republic of Tyva, Table 5) from the position of the $H_{n}$ RSS value of Russian regions is illustrated. 


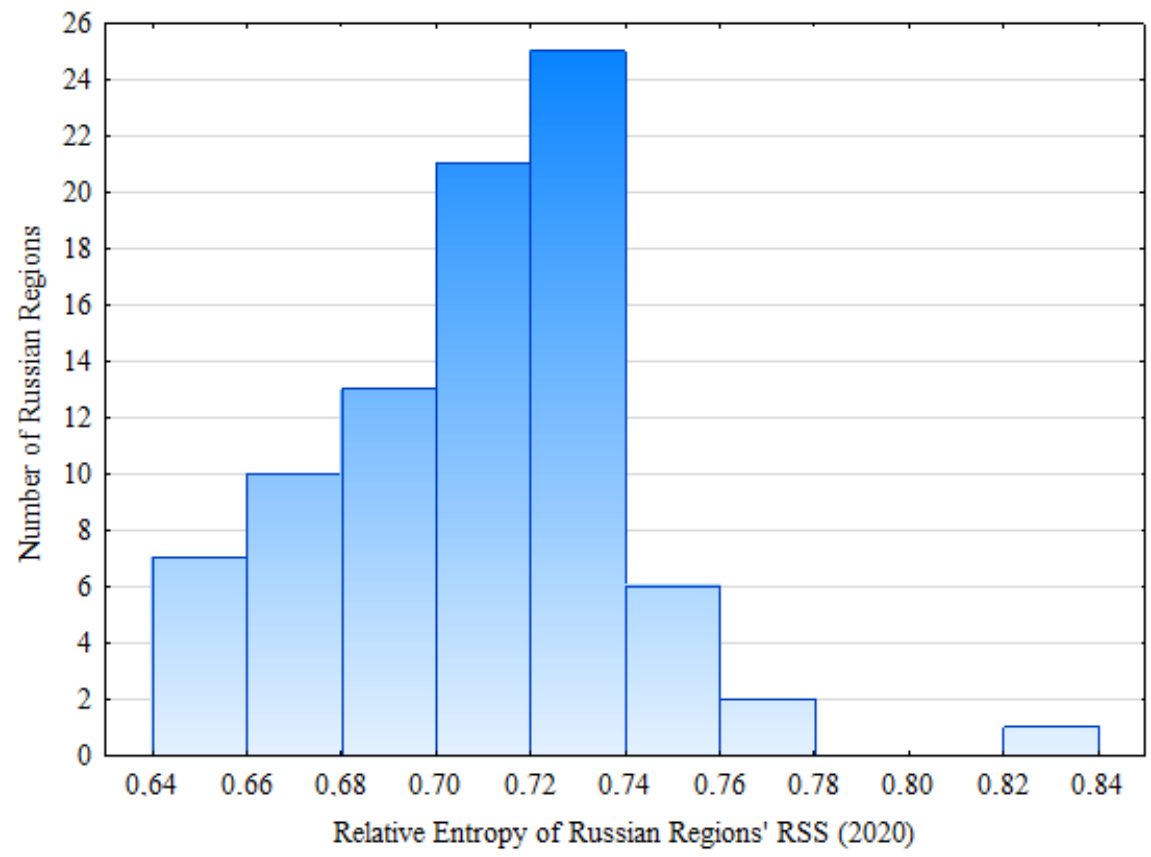

Figure 7. The distribution of the numerical values of the relative entropy $H_{n}$ RSS of regional road safety systems in 85 constituent entities of the Russian Federation (2020).

Table 4. Intermediate stages and the final result of calculating the relative entropy $H_{n}$ RSS of the road safety system of the Kamchatka Territory (2020)-the best region of the Russian Federation for this indicator.

\begin{tabular}{|c|c|c|c|c|}
\hline $\begin{array}{l}\text { Population }(P) \\
\text { in the } \\
\text { Kamchatka } \\
\text { Territory } \\
(2020), \\
\text { People [9] }\end{array}$ & $\begin{array}{c}\text { Fleet } \\
\text { of Vehicles } \\
(V h) \\
(2020), \\
\text { Vehicles [9] }\end{array}$ & $\begin{array}{c}\text { Number } \\
\text { of Road } \\
\text { Accidents } \\
\text { (RA Number) } \\
\text { (2020), } \\
\text { Units [9] }\end{array}$ & $\begin{array}{c}\text { Number } \\
\text { of Victims } \\
\text { (V Number) } \\
\text { in Road } \\
\text { Accidents (2020), } \\
\text { People [9] }\end{array}$ & $\begin{array}{c}\text { Number } \\
\text { of Deaths } \\
\text { (D Number) } \\
\text { in Road } \\
\text { Accidents } \\
\text { (2020), People [9] }\end{array}$ \\
\hline 311,667 & 213,559 & 471 & 678 & 47 \\
\hline \multicolumn{5}{|c|}{ Values of coefficients of information transmission between links of the cause-effect chain } \\
\hline & & $K_{R A}$ & $K_{V}$ & $K_{D}$ \\
\hline & & 0.0022 & 1.4395 & 0.0693 \\
\hline \multicolumn{5}{|c|}{ Positive of a link in the cause-and-effect chain $Q_{i}=\ln \left(1 / K_{i}\right)$ if $K_{i}<1$ or $Q_{i}=\ln \left(K_{i}\right)$ if $K_{i}>1$} \\
\hline 0.3 & & 6.1168 & 0.3643 & 2.6690 \\
\hline \multicolumn{5}{|c|}{ Relative weight of positive of a corresponding link in the chain $w_{i}$} \\
\hline 0.0 & & 0.6420 & 0.0382 & 0.2801 \\
\hline \multicolumn{5}{|c|}{ Estimated value $\left[\ln \left(w_{i}\right)\right]$} \\
\hline-3 & & -0.4432 & -3.2641 & -1.2725 \\
\hline \multicolumn{5}{|c|}{ Estimated value $\left[w_{i} \cdot \ln \left(w_{i}\right)\right]$} \\
\hline-0 . & & -0.2845 & -0.1248 & -0.3565 \\
\hline \multicolumn{5}{|c|}{ Estimated entropy value $H=-\sum_{i=1}^{n} w_{i} \cdot \ln w_{i}=0.894$} \\
\hline
\end{tabular}

Comparing the best and worst regions of Russia in terms of the orderliness of road safety systems, let us pay attention to the region's population and the number of road accidents comparable in magnitude, and quantitatively very different regional vehicle fleets, and the number of injured and killed in road traffic accidents. Analysis of the data in Tables 4 and 5 shows that the fundamental difference between the best and worst constituent entities of the Russian Federation in terms of entropy orderliness of road safety lies in the different transition coefficients $K_{i}$ of the cause-effect chain "Population $(P)$-The 
number of vehicles $\left(N_{V h}\right)$ - The number of road accidents $\left(N_{R A}\right)$ - The number of victims $\left(N_{V}\right)$-The number of deaths $\left(N_{D}\right)^{\prime \prime}$ (Table 6).

Table 5. Intermediate stages and the final result of calculating the relative entropy $H_{n}$ RSS of the road safety system of the Republic of Tyva (2020)-the worst region of the Russian Federation for this indicator.

\begin{tabular}{|c|c|c|c|c|}
\hline $\begin{array}{c}\text { Population }(P) \\
\text { in the } \\
\text { Republic } \\
\text { of Tyva (2020), } \\
\text { People [9] }\end{array}$ & $\begin{array}{c}\text { Fleet } \\
\text { of Vehicles } \\
(V h) \\
(2020), \\
\text { Vehicles [9] }\end{array}$ & $\begin{array}{c}\text { Number } \\
\text { of Road } \\
\text { Accidents } \\
\text { (RA Number) } \\
\text { (2020), } \\
\text { Units [9] }\end{array}$ & $\begin{array}{c}\text { Number } \\
\text { of Victims } \\
\text { (V Number) } \\
\text { in Road } \\
\text { Accidents (2020), } \\
\text { People [9] }\end{array}$ & $\begin{array}{c}\text { Number } \\
\text { of Deaths } \\
\text { (D Number) } \\
\text { in Road } \\
\text { Accidents } \\
\text { (2020), People [9] }\end{array}$ \\
\hline 330,368 & 70,452 & 472 & 855 & 101 \\
\hline \multicolumn{5}{|c|}{ Values of coefficients of information transmission between links of the cause-effect chain } \\
\hline$K$ & & $K_{R A}$ & $K_{V}$ & $K_{D}$ \\
\hline 0.2 & & 0.0067 & 1.8114 & 0.1181 \\
\hline \multicolumn{5}{|c|}{ Positive of a link in the cause-and-effect chain $Q_{i}=\ln \left(1 / K_{i}\right)$ if $K_{i}<1$ or $Q_{i}=\ln \left(K_{i}\right)$ if $K_{i}>1$} \\
\hline 1.5 & & 5.0057 & 0.5941 & 2.1360 \\
\hline \multicolumn{5}{|c|}{ Relative weight of positive of a corresponding link in the chain $w_{i}$} \\
\hline & & 0.5393 & 0.0640 & 0.2301 \\
\hline \multicolumn{5}{|c|}{ Estimated value $\left[\ln \left(w_{i}\right)\right]$} \\
\hline-1 & & -0.6174 & -2.7486 & -1.4691 \\
\hline \multicolumn{5}{|c|}{ Estimated value $\left[w_{i} \cdot \ln \left(w_{i}\right)\right]$} \\
\hline & & -0.3330 & -0.1760 & -0.3381 \\
\hline \multicolumn{5}{|c|}{ Estimated entropy value $H=-\sum_{i=1}^{n} w_{i} \cdot \ln w_{i}=1.146$} \\
\hline
\end{tabular}

Table 6. The fundamental difference between the numerical values of the information transmission coefficients between the links of the cause-effect chain of the road accident rate formation (2020).

\begin{tabular}{cccccc}
\hline $\begin{array}{c}\text { Compared } \\
\text { Road Safety } \\
\text { Systems }\end{array}$ & $H_{n R S S}$ & \multicolumn{3}{c}{ Values of Information Transfer Coefficients between Links } \\
of the Cause-Effect Chain
\end{tabular}

Note that for the Russian Federation, the values of $K_{i}$ of the cause-effect chain are intermediate in comparison with the best and worst regions (Table 6).

The best and worst Russian regions in terms of the orderliness of road safety systems differ significantly from each other both in motorization $\left(K_{N}\right.$ coefficient) and in the probability of a road accident ( $K_{R A}$ coefficient), in the average number of victims per one accident ( $K_{V}$ coefficient), and by the severity of the outcome of the road accident ( $K_{D}$ coefficient), and this difference is very significant.

Speculations about the reasons for this difference lead us to search for an answer in the social sphere. Table 7 shows some indicators characterizing the social and transport spheres of the two compared regions $[33,53]$.

It is easy to see that the rank analysis characterizes the Republic of Tyva as one of the worst regions of Russia from a social point of view. The Kamchatka Territory is one of the regional leaders. The assessment of the orderliness of the compared regional road safety management systems illustrates this thesis quite clearly. 
Table 7. Comparison of the best and worst constituent entities of the Russian Federation in terms of orderliness of regional road safety systems $(2020)[33,53]$.

\begin{tabular}{|c|c|c|c|}
\hline \multirow[b]{2}{*}{ Indicator } & \multicolumn{3}{|c|}{ Indicator Values/Rank № Out of 85} \\
\hline & $\begin{array}{c}\text { Kamchatka } \\
\text { Territory }\end{array}$ & $\begin{array}{c}\text { Russian } \\
\text { Federation }\end{array}$ & $\begin{array}{c}\text { Republic } \\
\text { of Tyva }\end{array}$ \\
\hline \multicolumn{4}{|c|}{ Characteristics of the socio-economic sphere [33] } \\
\hline $\begin{array}{l}\text { Gross regional product, } \\
\text { thous. rubles/person per year }\end{array}$ & $891.0 / 11$ & $735.1 /-$ & $243.1 / 80$ \\
\hline $\begin{array}{l}\text { Specific volume of expenditures of the budget of a } \\
\text { constituent entity of the Russian Federation, thous. } \\
\text { rubles/person per year }\end{array}$ & $309.3 / 9$ & $156.9 /-$ & $128.2 / 63$ \\
\hline Unemployment, \% of the labor force & $3.8 / 5$ & $5.8 /-$ & $18.0 / 82$ \\
\hline \multicolumn{4}{|c|}{ Characteristics of regional transport systems [53] } \\
\hline $\begin{array}{l}\text { Motorization of the population, } \\
\text { vehicles } / 1000 \text { people }\end{array}$ & $685.2 / 1$ & $401.6 /-$ & $213.3 / 85$ \\
\hline Estimated traffic density, vehicle $/ 1 \mathrm{~km}$ & $94.5 / 5$ & $33.2 /-$ & $7.9 / 84$ \\
\hline Transport Risk TR, road deaths / 100 thous. vehicles & $22.0 / 17$ & $26.8 /-$ & $143.4 / 85$ \\
\hline
\end{tabular}

\section{Spatio-Temporal Patterns of Changes in the Orderliness of Road Safety Systems in} the Russian Federation

6.1. Patterns of the Distribution of Regional Values of the Relative Entropy of Road Safety Systems $H_{n}$ RSS in Russia in Space (2020)

Today (2020), the most favorable situation in terms of the orderliness of road safety systems is observed in the economically prosperous regions of the country-in the Ural $\left(H_{n} R S S=0.695\right)$ and Central $\left(H_{n}\right.$ RSS $\left.=0.697\right)$ Federal Districts. There is also a fairly high level of orderliness in the field of road safety in the Far Eastern Federal District $\left(H_{n} R S S=0.697\right)$. On the contrary, the situation is much worse in the economically unfavorable North Caucasian Federal Districts $\left(H_{n} R S S=0.736\right)$ and Siberian Federal Districts $\left(H_{n} R S S=0.716\right)$. Other Federal Districts of the country are intermediate in relation to the leaders and outsiders.

The distribution of numerical values of the relative entropy $H_{n}$ RSS of regional road safety systems in 85 constituent entities of the Russian Federation (2020), shown in Figure 7, is given in Table 8 .

Table 8. Distribution of regions of the Russian Federation by value ranges of the relative entropy $H_{n}$ RSS of regional road safety systems (2020).

\begin{tabular}{|c|c|c|c|c|c|c|c|c|c|}
\hline \multicolumn{10}{|c|}{$\begin{array}{l}\text { The Number of Regions of the Russian Federation ( } 85 \text { in Total) for Whose Road Safety Systems } \\
\text { the Relative Entropy } H_{n} R S S \text { of Regional Road Safety Systems Is in the Value Ranges }\end{array}$} \\
\hline$[0.645$ & {$[0.661$} & {$[0.681$} & {$[0.701 ;$} & {$[0.721$} & {$[0.741 ;$} & {$[0.761 ;$} & {$[0.781$} & {$[0.801 ;$} & {$[0.821 ;$} \\
\hline 0.660$]$ & $0.680]$ & $0.700]$ & $0.720]$ & $0.740]$ & $0.760]$ & $0.780]$ & $0.800]$ & $0.820]$ & $0.826]$ \\
\hline 7 & 10 & 13 & 21 & 25 & 6 & 2 & - & - & 1 \\
\hline \multicolumn{10}{|c|}{ Actual (2020) orderliness of regional road safety systems } \\
\hline \multicolumn{2}{|c|}{ High } & \multicolumn{2}{|c|}{ Average } & \multicolumn{2}{|c|}{ Low } & & \multicolumn{2}{|c|}{ Very low } & \\
\hline
\end{tabular}

Table 9 shows the best three and the worst three regions of the Russian Federation in terms of orderliness of road safety systems.

Table 9. The best and worst regions in Russia by the value of the relative entropy $H_{n}$ RSS (2020).

\begin{tabular}{|c|c|c|c|}
\hline \multicolumn{4}{|c|}{ Regions of the Russian Federation } \\
\hline $\begin{array}{c}\text { The Best in Terms of Orderliness } \\
\text { of Road Safety Systems }\end{array}$ & $H_{n R S S}$ & $\begin{array}{c}\text { The Worst in Terms of Orderliness } \\
\text { of Road Safety Systems }\end{array}$ & $H_{n} R S S$ \\
\hline Kamchatka Territory & 0.645 & Republic of Tuva & 0.826 \\
\hline Pskov Region & 0.655 & Republic of Ingushetia & 0.778 \\
\hline Sverdlovsk Region & 0.657 & Karachayevo-Circassian Republic & 0.773 \\
\hline
\end{tabular}


Let us look at the example from Section 2.2 (Figure 3, Table 2) comparing the quality of regional road safety systems in the neighboring Moscow and Vladimir regions. The characteristic of the level of their orderliness is very different.

The relative entropy of the regional road safety system of the Moscow region $H_{n}$ RSS of the Moscow region $=0.662$; the same for the Vladimir region $H_{n}$ RSS of the Vladimir region $=0.738$. Thus, the Moscow region can be attributed to the regions of Russia with a high level of orderliness of the regional road safety system, and the Vladimir region-to the regions with a low level of road safety orderliness.

Here, as in the case of comparing the Republic of Tyva and the Kamchatka Territory (Table 7), these two regions are at opposite poles in terms of their socio-economic development.

The Moscow region in most positions in Russia takes $2-4$ th places, while the Vladimir region ranks among the 60-70th [33].

6.2. Patterns of Changes in the Relative Entropy of Road Safety Systems $H_{n}$ RSS of the Federal Districts of Russia in Time

Table 10 shows data characterizing changes in the relative entropy of the Russian road safety system $H_{n} R S S$ in 2004-2020. It is easy to see that, in dynamics (2004-2020), the relative entropy of the road safety system in Russia decreases, which means that its orderliness increases. Over the course of 17 years, the all-Russian value of $H_{n}$ RSS has decreased by $9.7 \%$.

Table 10. Changes in the relative entropy $H_{n}$ RSS of the Russian road safety system in 2004-2020.

\begin{tabular}{|c|c|c|c|c|c|c|c|c|}
\hline \multirow{2}{*}{ System } & \multicolumn{8}{|c|}{ Value Relative Entropy of Road Safety Systems $H_{n} R S S$ in the Russian Federation/Years } \\
\hline & 2004 & 2005 & 2006 & 2007 & 2008 & 2009 & 2010 & 2011 \\
\hline Russia & 0.782 & 0.783 & 0.783 & 0.781 & 0.769 & 0.762 & 0.759 & 0.755 \\
\hline \multicolumn{9}{|c|}{ Value relative entropy of road safety systems $H_{n} R S S$ in the Russian Federation/Years } \\
\hline 2012 & 2013 & 2014 & 2015 & 2016 & 2017 & 2018 & 2019 & 2020 \\
\hline 0.764 & 0.745 & 0.734 & 0.720 & 0.718 & 0.713 & 0.712 & 0.710 & 0.707 \\
\hline
\end{tabular}

Figure 8 shows the time series (2004-2020) of changes in the relative entropy of the road safety system $H_{n}$ RSS of the Russian Federation.

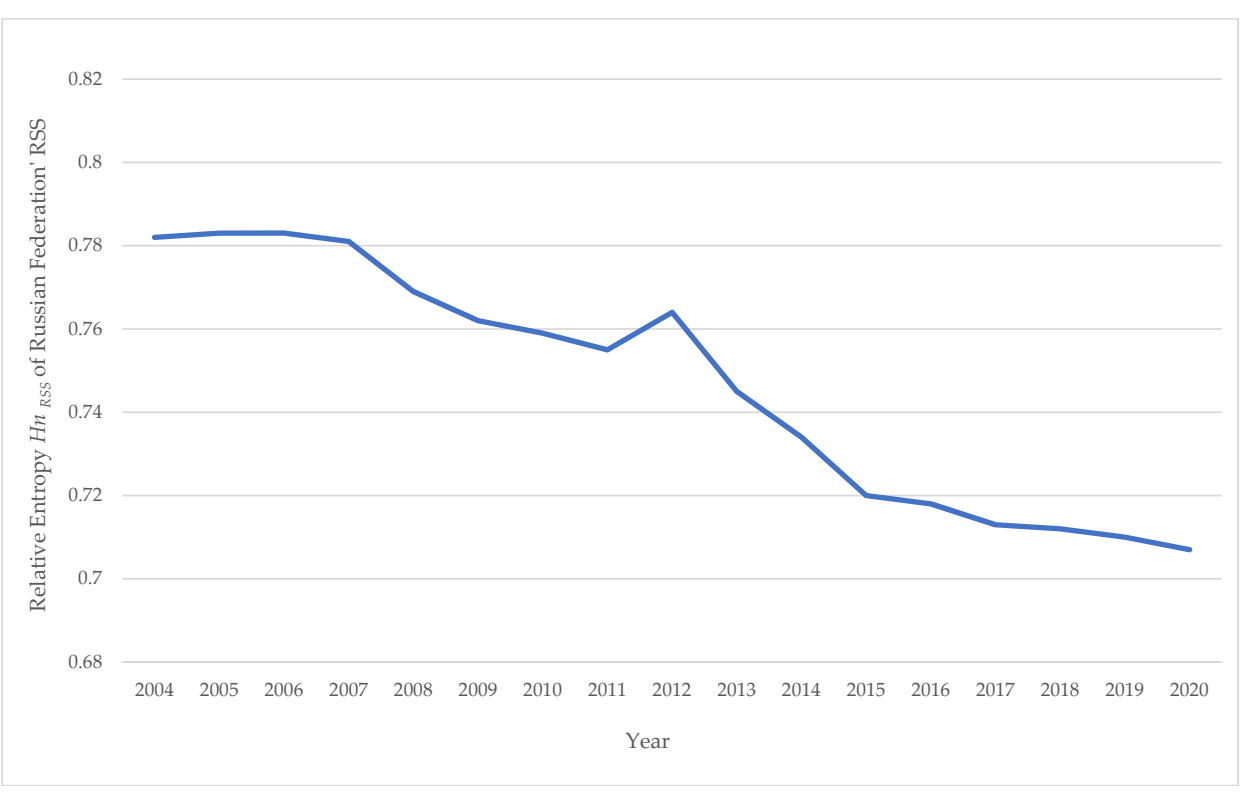

Figure 8. Changes (2004-2020) in the relative entropy of the road safety system $H_{n} R S S$ of the Russian Federation. 
In general, the dynamics of the process of decreasing the relative entropy of the Russian road safety system is described by the linear equation $H_{n} R S S R F=11.9263-0.0056 \cdot$ Year. Table 11 shows data on the relative entropy of road safety systems $H_{n}$ RSS of the Federal Districts of Russia in dynamics in 2004-2020.

Table 11. Changes in the relative entropy of road safety systems $H_{n}$ RSS of the Federal Districts of Russia in dynamics in 2004-2020.

\begin{tabular}{|c|c|c|c|c|c|c|c|c|}
\hline \multirow{2}{*}{ Year } & \multicolumn{8}{|c|}{ Value Relative Entropy of Road Safety Systems $H_{n} R S S$ in the Federal Districts of Russian Federation } \\
\hline & $C F D$ & NWFD & $S F D$ & NCFD & $V F D$ & UFD & SFD & FEFD \\
\hline 2004 & 0.790 & 0.779 & 0.762 & 0.796 & 0.773 & 0.789 & 0.783 & 0.779 \\
\hline 2005 & 0.782 & 0.783 & 0.764 & 0.800 & 0.779 & 0.793 & 0.784 & 0.784 \\
\hline 2006 & 0.779 & 0.781 & 0.765 & 0.795 & 0.783 & 0.790 & 0.787 & 0.785 \\
\hline 2007 & 0.777 & 0.774 & 0.765 & 0.797 & 0.780 & 0.783 & 0.782 & 0.789 \\
\hline 2008 & 0.763 & 0.763 & 0.758 & 0.791 & 0.772 & 0.771 & 0.773 & 0.778 \\
\hline 2009 & 0.755 & 0.754 & 0.751 & 0.786 & 0.765 & 0.760 & 0.763 & 0.768 \\
\hline 2010 & 0.752 & 0.756 & 0.750 & 0.777 & 0.765 & 0.758 & 0.761 & 0.751 \\
\hline 2011 & 0.747 & 0.753 & 0.749 & 0.773 & 0.762 & 0.751 & 0.758 & 0.748 \\
\hline 2012 & 0.742 & 0.750 & 0.745 & 0.772 & 0.757 & 0.749 & 0.754 & 0.758 \\
\hline 2013 & 0.734 & 0.745 & 0.740 & 0.764 & 0.755 & 0.738 & 0.750 & 0.739 \\
\hline 2014 & 0.724 & 0.735 & 0.722 & 0.751 & 0.743 & 0.724 & 0.736 & 0.729 \\
\hline 2015 & 0.713 & 0.718 & 0.717 & 0.741 & 0.727 & 0.705 & 0.726 & 0.713 \\
\hline 2016 & 0.707 & 0.711 & 0.710 & 0.746 & 0.727 & 0.704 & 0.730 & 0.715 \\
\hline 2017 & 0.702 & 0.707 & 0.705 & 0.747 & 0.721 & 0.701 & 0.724 & 0.709 \\
\hline 2018 & 0.704 & 0.709 & 0.704 & 0.743 & 0.717 & 0.700 & 0.722 & 0.707 \\
\hline 2019 & 0.701 & 0.706 & 0.705 & 0.740 & 0.715 & 0.697 & 0.719 & 0.702 \\
\hline 2020 & 0.697 & 0.704 & 0.704 & 0.736 & 0.713 & 0.695 & 0.716 & 0.697 \\
\hline
\end{tabular}

Note. CFD-Central Federal District; NWFD-North-Western Federal District; SFD-Southern Federal District; NCFD—North Caucasus Federal District; VFD—Volga Federal District; UFD—Ural Federal District; SFD—Siberian Federal District; FEFD—Far Eastern Federal District.

Figure 9 shows the corresponding time series of $H_{n}$ RSS FD values, constructed from the data in Table 11.

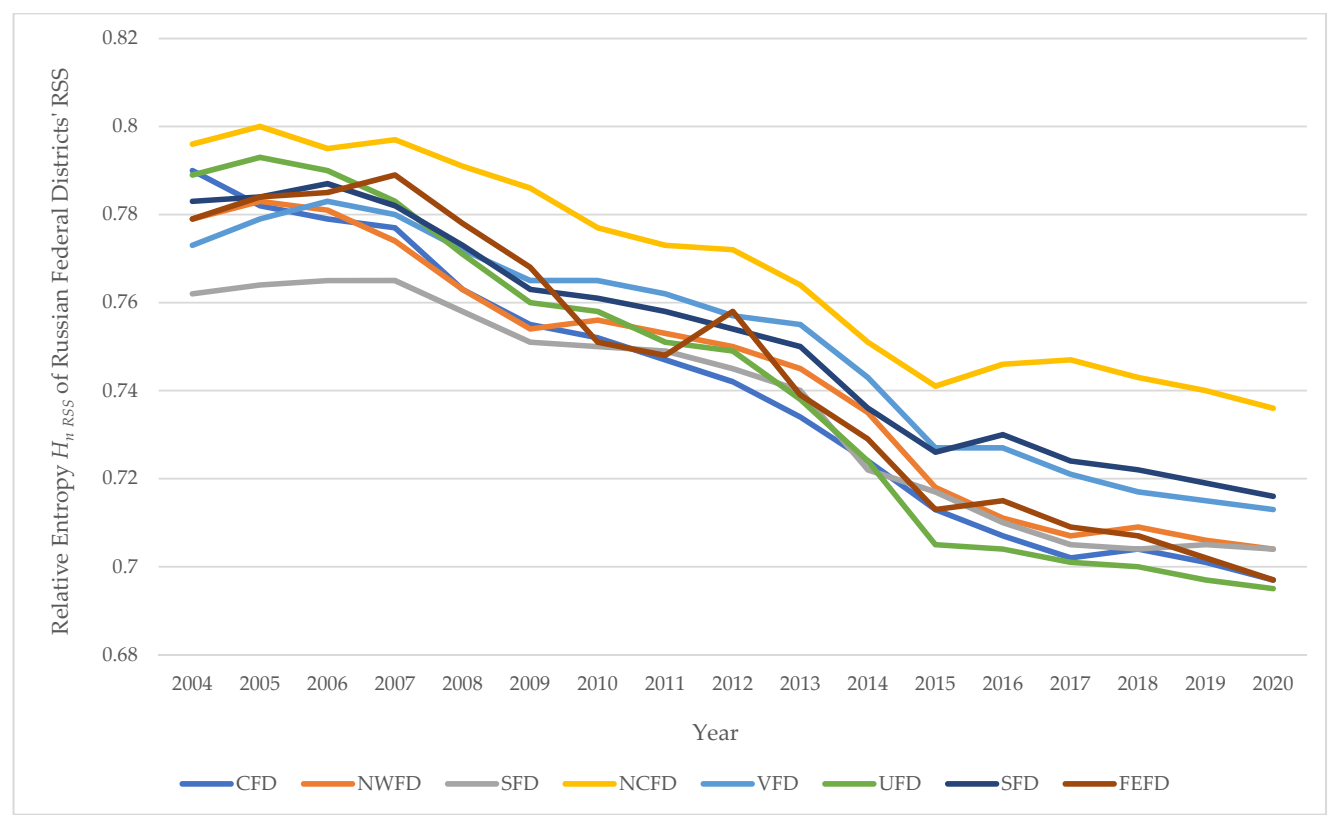

Figure 9. Time series (2004-2020) of the values of the relative entropy $H_{n}$ RSS of the Federal Districts of the Russian Federation. 
Table 12 shows the models of $H_{n}$ RSS FD $=a-b \cdot$ Year, describing the process of changes in time of the relative entropy $H_{n}$ RSS of the road safety systems of the Federal Districts of the Russian Federation. The data in Table 12 and Figure 9 allow us to conclude that in different regions of Russia the dynamics of improving the orderliness of road safety systems is different. The most important feature that identifies the quality of road safety management is the rate (speed of the process per unit of time) of positive changes in the controlled system.

Table 12. Models of $H_{n} R S S F D=a-b \cdot$ Year for the road safety systems of the Federal Districts of the Russian Federation.

\begin{tabular}{cc}
\hline Federal Districts of Russian Federation & Model of $\boldsymbol{H}_{\boldsymbol{n} \text { RSS FD }}=\boldsymbol{a}-\boldsymbol{b} \cdot$ Year \\
\hline North Caucasus Federal District (NCFD) & $H_{n}$ RSS NCFD $=9.8318-0.0045 \cdot$ Year \\
Southern Federal District (SFD) & $H_{n}$ RSS SFD $=10.1157-0.0047 \cdot$ Year \\
Volga Federal District (VFD) & $H_{n}$ RSS VFD $=10.4355-0.0048 \cdot$ Year \\
Siberian Federal District (SFD) & $H_{n}$ RSS SFD $=10.6730-0.0049 \cdot$ Year \\
North-Western Federal District (NWFD) & $H_{n}$ RSS NWFD $=11.9469-0.0056 \cdot$ Year \\
Central Federal District (CFD) & $H_{n} R S S$ CFD $=13.3390-0.0063 \cdot$ Year \\
Far Eastern Federal District (FEFD) & $H_{n}$ RSS FEFD $=13.4079-0.0063 \cdot$ Year \\
Ural Federal District (UFD) & $H_{n \text { RSS UFD }}=14.9835-0.0071 \cdot$ Year
\end{tabular}

Note. The order of presentation of the Federal Districts in Table 12 is determined by the rank of the rate of change of the relative entropy $H_{n}$ RSS FD (according to the value of the parameter $\mathrm{b}$ of the model)-from the lowest to the highest.

The conclusion about the quality of road safety management can be drawn from the results of the analysis of the value of the parameter $\mathrm{b}$ in the model of $H_{n}$ RSS FD $=a-b \cdot$ Year.

Table 13 presents the numerical values of this coefficient for models describing the dynamics of the process in time for the Federal Districts of the Russian Federation.

Table 13. Identification of the rate and quality of the process of dynamics of the orderliness of road safety systems of the Federal Districts of Russia in 2004-2020.

\begin{tabular}{|c|c|c|c|c|c|c|c|}
\hline \multicolumn{8}{|c|}{ Value of the Parameter $b$ in the Model of $H_{n} R S S F D=a-b \cdot$ Year for the Federal Districts of the Russian Federation } \\
\hline CFD & NWFD & SFD & NCFD & $V F D$ & UFD & SFD & FEFD \\
\hline 0.0063 & 0.0056 & 0.0047 & 0.0045 & 0.0048 & 0.0071 & 0.0049 & 0.0063 \\
\hline \multicolumn{8}{|c|}{ Quality of the process of dynamics of the orderliness of road safety systems } \\
\hline $\begin{array}{c}\text { Above } \\
\text { average }\end{array}$ & Average & $\begin{array}{l}\text { Below } \\
\text { average }\end{array}$ & Low & $\begin{array}{c}\text { Below } \\
\text { average }\end{array}$ & High & $\begin{array}{c}\text { Below } \\
\text { average }\end{array}$ & $\begin{array}{c}\text { Above } \\
\text { average }\end{array}$ \\
\hline
\end{tabular}

Note. The quality of the dynamics process is identified by the value of the parameter $b: \leq 0.0045-1$ low; $0.0046 \ldots$ 0.0055 -below average; $0.0056 \ldots 0.0060$-average; $0.0061 \ldots 0.0070$-above average; $\geq 0.0071$-high.

In the Ural Federal District, the rate of an increase in road safety orderliness is the maximum, and in the North Caucasian Federal District, it is the minimum.

Thus, in terms of the rate of an increase in the orderliness of the road safety systems of the Federal Districts, the best situation is in the Ural Federal District, and the worst is in the North Caucasian Federal District.

This information is very useful precisely for understanding the essence of what is happening in this area and is the basis for taking specific measures at the Federal level of road safety management.

\section{Discussion of the Results}

What determines the dynamics of a decrease in the system entropy $H$ and, at the same time, an increase in the orderliness of road safety? First of all, the mentality of humans and their behavior on the road. Discussing the dynamics of orderliness in the field of road safety and stating the positive rate of its growth, we try to find evidence of a positive change in the mentality of the Russian driver. The best tool for this are opinion polls of the population. 
The leading Russian journal for motorists «Za Rulem» [54] quite regularly (from 2012 to the present) conducts opinion polls of its readers. Usually several thousand respondents take part in the polls, and their results are representative. Below are screenshots of the comparative (for different years) results of the distribution of answers to two most important questions-about the attitude to the compulsory observance of the Road Traffic Rules (Figure 10) and the use of seat belts (Figure 11).

It is easy to see that over time, the proportion of Russian drivers who obey the law and practice safe behavior is gradually increasing. This largely explains the general tendency towards a decrease in the level of entropy of road safety systems $H_{n}$ RSS. The regional diversity of this general trend is explained by the effect of many other factors, such as the quality of the vehicle fleet [55], the quality of the road transport infrastructure [56], and the general quality of life of the population [57].

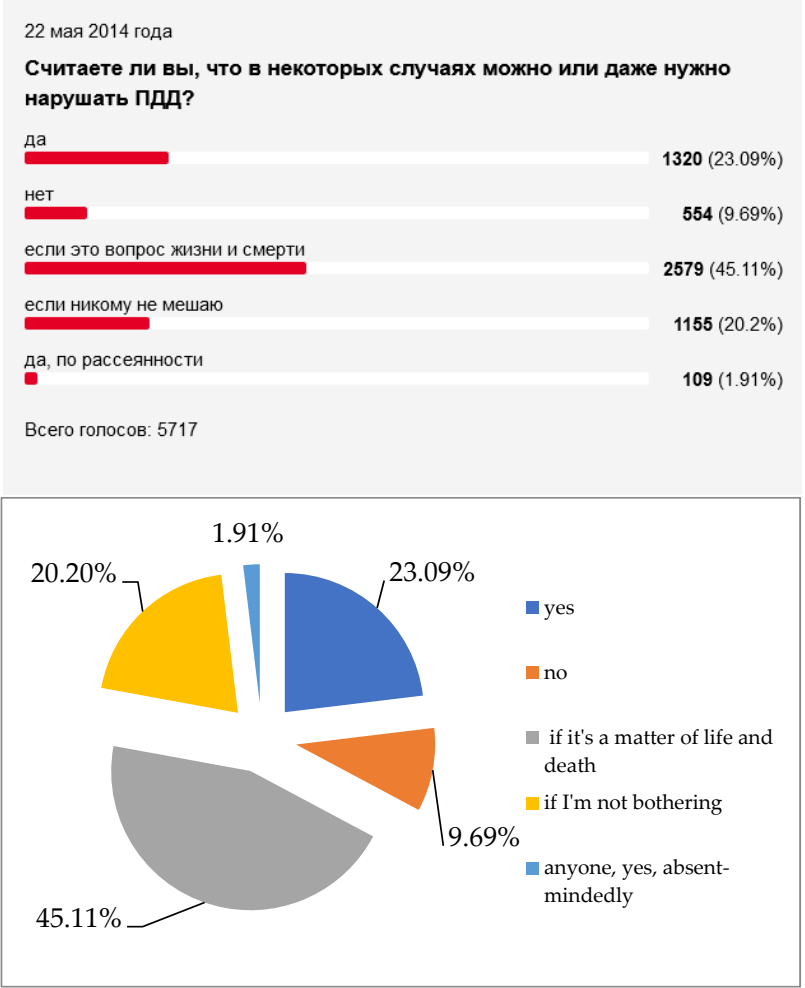

(a)

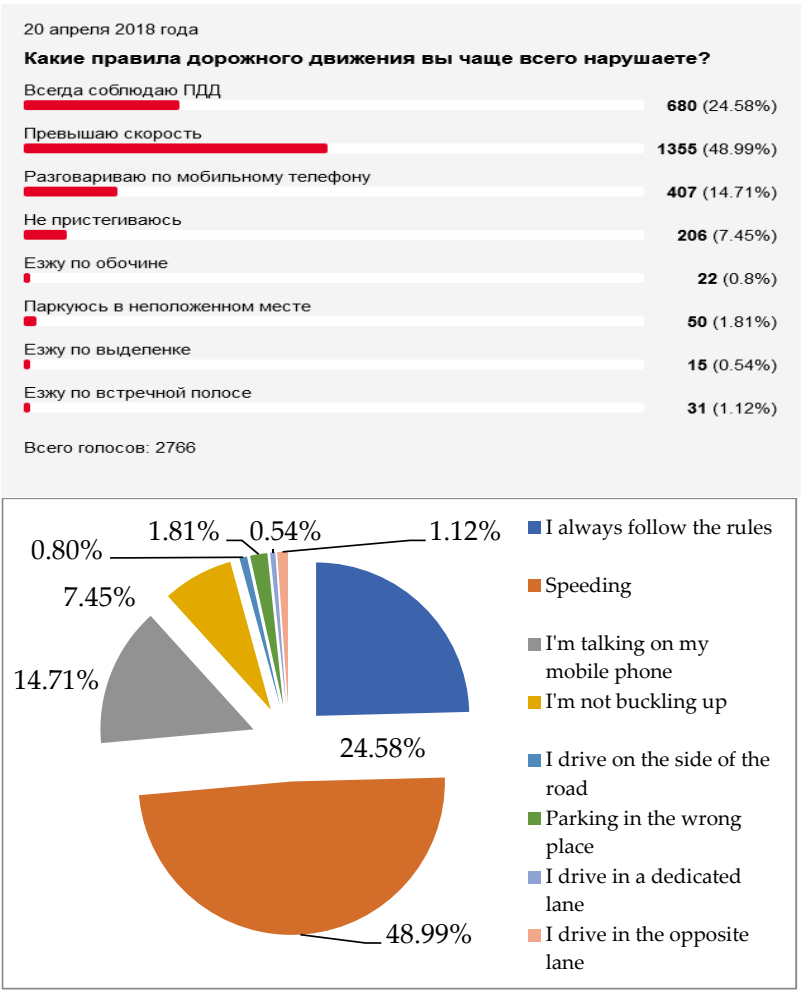

(b)

Figure 10. The results of opinion polls regarding the compulsory observance of the road traffic rules by Russian drivers [54]. (a) Results as of 22.05.2014 ( $\mathrm{N}=5717) \%$ of total loyalty to traffic rules $=9.69 \%$. (b) Results as of 20.04.2018 ( $\mathrm{N}=2766) \%$ of total loyalty to traffic rules $=24.58 \%$. 


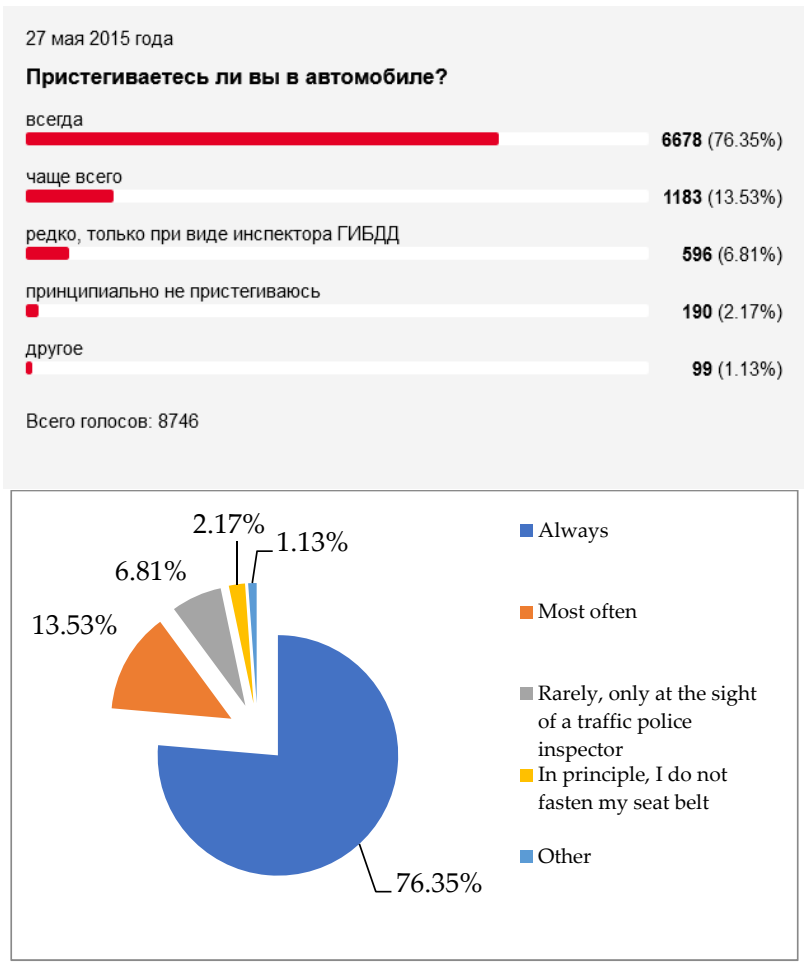

(a)

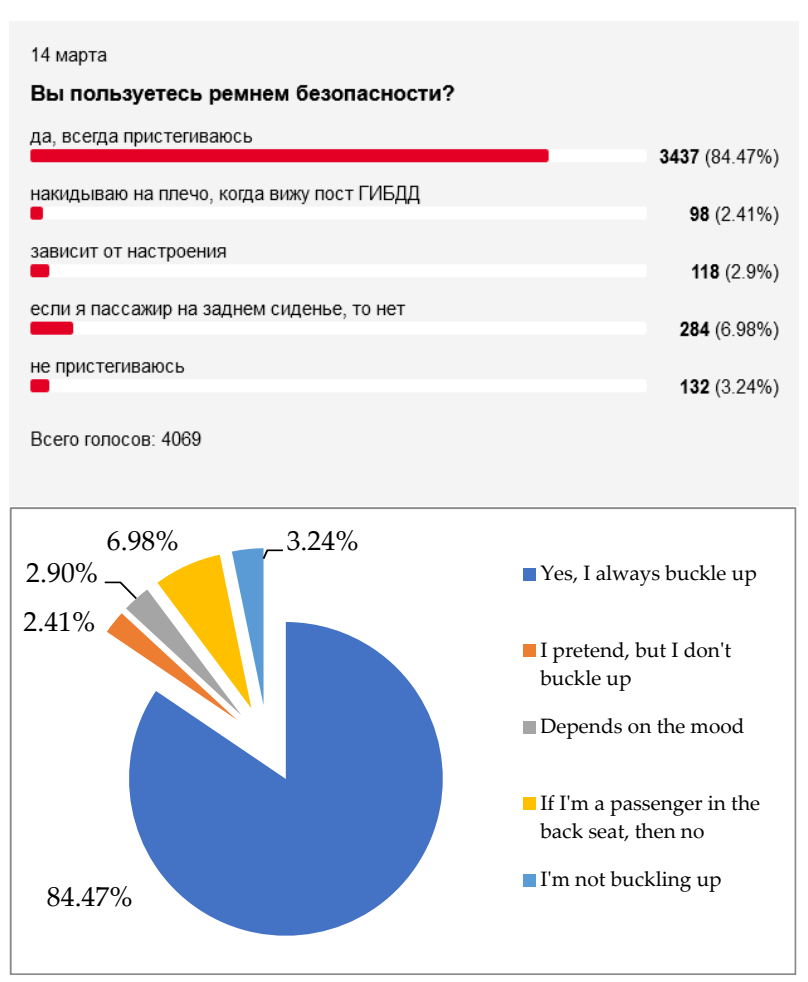

(b)

Figure 11. The results of opinion polls regarding the use of seat belts by Russian drivers [54]. (a) Results as of 27.05 .2015 ( $\mathrm{N}=8746) \%$ of belt users $=76.35 \%$. (b) Results as of $14.03 .2019(\mathrm{~N}=4069) \%$ of belt users $=84.47 \%$.

\section{Conclusions}

In conclusion, I would like to point out the main results obtained in the course of the research.

First, the entropy method can be successfully used in road safety management in large federal countries with a complex administrative structure. The continuous complication of transport systems, the growth of automobilization, and people's transport mobility require more professional system management. This issue has not been successfully solved in every case. As a consequence, high heterogeneity of the quality of the regional transport system functioning, including the road safety provision sphere, occurs. The problem has especially manifested itself in large countries (Russian Federation, USA, China, Brazil, Canada, Australia, etc). Nowadays, the problem of the absence of the methodology of the fair, from the regions' view, road safety management clearly manifests itself at the federal level in Russia. Primarily, it concerns the distribution of the resources, required for the provision of high-level road safety, between regions. Another problem, typical for road safety management in large federal countries, is the necessity of the proper and professional statement of different target levels for different countries' regions. The choice of suitable methodological approaches of road safety provision for certain places is also important. That is the exact purpose of federal road safety management. However, for now, federal authorities do not have ideal instruments for the comparison of road safety spheres in different country's regions.

Second, it is the indicator of relative entropy $H_{n \text { RSS }}$ that makes it possible to quantify the orderliness of the regional road safety system. This indicator has an important advantage-it can be used to identify the structural perfection of the road safety system, which allows us to compare systems that are completely different in size. Another significant advantage of this indicator over other characteristics of the assessment of road safety, 
such as social risk, transport risk, and the coefficient of road accident severity, is complexity. This indicator embodies all advantages of other characteristics of road safety assessment.

Third, the assessment of the relative entropy $H_{n}$ RSS of the Russian regional road safety systems shows that the orderliness in the road safety sphere in Russia varies over a wide range of values of $H_{n}$ RF RSS $2020=[0.645 ; 0.826]$, and the rate of its decline in 2004-2020 varies for different regions of the country. It is an important conclusion that allows one to both comprehensively and differentially for regions assess the general situation in the sphere of the road safety provision in Russia. The knowledge of general and partial regularities of changes of relative entropy $H_{n}$ RSS of Russian regional road safety provision systems in time and space allows one to develop and use differentiated approaches for different regions in federal management.

Fourth, the leaders and outsiders among Russian regions were identified in terms of the current level of orderliness of regional road safety systems and in terms of the rate of its increase. In particular, in recent years, the Ural Federal District is the leader of the rate of increase in the orderliness of regional road safety provision systems. Vice versa, the North Caucasian Federal District is the outsider in this sphere. The analytics of the current situation (2020) of the road safety orderliness in administrative regions showed that Kamchatka Krai is leading $\left(H_{n \text { Kamchatka } R S S ~ 2020}=0.645\right)$ and the Tyva Republic has the worst result $\left(H_{n}\right.$ Tyva RSS 2020 $\left.=0.826\right)$.

Fifth, a methodology for road safety management in large-scale systems using the entropy method was developed. The algorithm of the management of the regional road safety in Russia concerning the level of its entropic orderliness is presented in Section 4.

Sixth, an attempt was made to explain the trends of increasing orderliness in the field of road safety by positive changes in the mentality of Russian drivers. I believe that this is an essential conclusion of the research because it is always worth knowing what generates positive effects in the state of the managed systems. Statistics presented in the article partially demonstrate that, in recent years, the transport culture of road traffic participants has gradually improved in Russia.

Most likely, the next step in my study will be measuring the predictability and complexity of time series using entropy [58].

Summarizing what is above, I would like to express hope for a gradual improvement of the road safety situation in Russia. Despite the fact that today Russia significantly lags behind the world leaders in road safety-the Scandinavian countries, Great Britain, Ireland, and Switzerland (Table 1)-it is still moving along a positive path to reduce chaos in transport systems and improve orderliness in the field of road safety. This is evidenced by the results of the studies. The use of the entropy method of road safety management can accelerate this process.

Funding: This research was funded by Russian Ministry of Education and Science, grant number No. 0825-2020-0014, 2020-2022 «New patterns and solutions for the functioning of urban transport systems in the paradigm "Transition from owning a personal car to mobility as a service"».

Data Availability Statement: Not applicable.

Acknowledgments: The author would like to thank the Russian Ministry of Education and Science on the project: «New patterns and solutions for the functioning of urban transport systems in the paradigm "Transition from owning a personal car to mobility as a service"» (No. 0825-2020-0014, 2020-2022). The author would like to thank the anonymous referees for their very useful suggestions.

Conflicts of Interest: The author declares no conflict of interest.

\section{References}

1. Blinkin, M.Y.; Reshetova, E.M. Road Safety: The History of the Issue, International Experience, Basic Institutions; Publishing House of the Higher School of Economics: Moscow, Russia, 2013; 240p. (In Russian)

2. Elvik, R.; Goel, R. Safety-in-numbers: An updated meta-analysis of estimates. Accid. Anal. Prev. 2019, 129, 136-147. [CrossRef] [PubMed] 
3. Bener, A.; Abu-Zidan, F.M.; Bensiali, A.K.; Al-Mulla, A.; Jadaan, K.S. Strategy to improve road safety in developing countries. Saudi Med. J. 2003, 24, 603-608. [PubMed]

4. Zubarevich, N.V. Spatial development Strategy: Priorities and instruments. Vopr. Èkon. 2019, 1, 135-145. (In Russian) [CrossRef]

5. Ma, Y.; Tang, K.; Chen, S.; Khattak, A.J.; Pan, Y. On-line aggressive driving identification based on in-vehicle kinematic parameters under naturalistic driving conditions. Transp. Res. Part C Emerg. Technol. 2020, 114, 554-571. [CrossRef]

6. Bao, Q.; Tang, H.; Shen, Y. Driving Behavior Based Relative Risk Evaluation Using a Nonparametric Optimization Method. Int. J. Environ. Res. Public Health 2021, 18, 12452. [CrossRef]

7. Decree of the Government of the Russian Federation № 864 Dated 03.10.2013 «On the Federal Target Program «Improving Road Safety in 2013-2020» (with Amendments and Additions»). Available online: http://government.ru/docs/7050/ (accessed on 4 November 2021). (In Russian).

8. Decree of the Government of the Russian Federation № 1-r Dated 08.01.2018 «Road Safety Strategy of the Russian Federation for 2018-2024». Available online: http:/ / static.government.ru \T1 \guilsinglrightmedia/files / protect \relax \let\$ mathsurround $\backslash$ $\mathrm{z} @ \backslash$ protect \mathinner $\backslash$ ldotp $\backslash$ ldotp $\backslash$ ldotp $\} \backslash$ protect $\backslash$ leavevmode@ifvmode $\backslash$ kern+.1667em $\backslash$ relax $\$$ unhbox $\backslash v o i d b @ x \backslash$

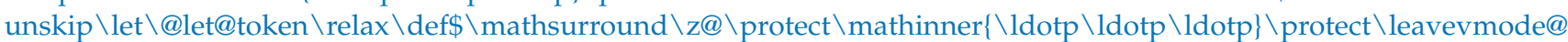
ifvmode $\backslash$ kern+.1667em $\backslash$ relax $\$\{\$$ mathsurround $\backslash z @ \backslash$ protect $\backslash$ mathinner $\backslash \backslash$ ldotp $\backslash$ ldotp $\backslash$ ldotp $\} \backslash$ protect $\backslash$ leavevmode@

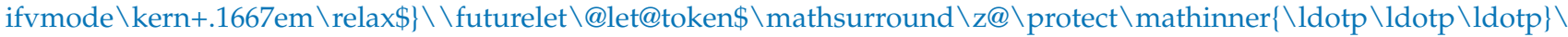

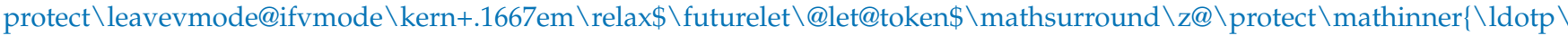
ldotp \ldotp $\} \backslash$ protect $\backslash$ leavevmode@ifvmode $\backslash$ kern+.1667em $\backslash$ relax\$pdf (accessed on 4 November 2021). (In Russian)

9. Website of the Scientific Center of the Road Safety of the Ministry of Internal Affairs of the Russian Federation. Road Traffic Accidents in the Russian Federation for 2020. Informational and Analytical Review; Publishing House «Scientific Center for Road Safety of the Ministry of Internal Affairs of Russia»: Moscow, Russia, 2021; 79p. (In Russian)

10. Petrov, A.; Evtyukov, S. Analysis of possibilities for achieving targets of Russian Road Safety Strategy. Transp. Res. Procedia 2020, 50, 518-527. [CrossRef]

11. Mayorov, V.I.; Sevryugin, V.E. International experience of developing complex target programs of road users' safety. Criminol. J. Baikal Natl. Univ. Econ. Law 2015, 9, 766-776. (In Russian) [CrossRef]

12. IRTAD Road Safety Database. 2020. Available online: https://trimis.ec.europa.eu/project/international-road-traffic-andaccident-database (accessed on 8 November 2021).

13. Pyankova, A.; Fattakhov, T. Mortality from road traffic accidents in Russia: Approaches to assessment, trends and prospects. Demogr. Rev. 2019, 6, 58-84. (In Russian) [CrossRef]

14. Decree of the President of the Russian Federation № 474 Dated 21.07.2020 «On the National Development Goals of the Russian Federation for the Period Up to 2030». Available online: http:/ / www.kremlin.ru/acts/bank/45726 (accessed on 10 November 2021). (In Russian).

15. Vision Zero Homepage. Vision Zero. Available online: https://visionzero.global/ (accessed on 11 November 2021).

16. Safarpour, H.; Khorasani-Zavareh, D.; Mohammadi, R. The common road safety approaches: A scoping review and thematic analysis. Chin. J. Traumatol. 2020, 23, 113-121. [CrossRef]

17. National Project of Russian Federation "Safe and High-Quality Highways". Available online: http://government.ru/ rugovclassifier/844/events/ (accessed on 13 November 2021). (In Russian).

18. Amiril, A.; Nawawi, A.H.; Takim, R.; Latif, S.N.F.A. Transportation Infrastructure Project Sustainability Factors and Performance. Procedia-Soc. Behav. Sci. 2014, 153, 90-98. [CrossRef]

19. Wong, H.L.; Luo, R.; Zhang, L.; Rozelle, S. Providing quality infrastructure in rural villages: The case of rural roads in China. J. Dev. Econ. 2013, 103, 262-274. [CrossRef]

20. Morozov, V.; Iarkov, S. Formation of the Traffic Flow Rate under the Influence of Traffic Flow Concentration in Time at Controlled Intersections in Tyumen, Russian Federation. Sustainability 2021, 13, 8324. [CrossRef]

21. Zakharov, D.; Fadyushin, A. The Efficiency of some Activities for the Development of Urban Infrastructure for Public Transport, Cyclists and Pedestrians. Int. J. Transp. Dev. Integr. 2021, 5, 136-149. [CrossRef]

22. Farooq, D.; Moslem, S.; Tufail, R.F.; Ghorbanzadeh, O.; Duleba, S.; Maqsoom, A.; Blaschke, T. Analyzing the Importance of Driver Behavior Criteria Related to Road Safety for Different Driving Cultures. Int. J. Environ. Res. Public Health 2020, 17, 1893. [CrossRef]

23. Fang, C.; Zhang, Y.; Zhang, M.; Fang, Q. P300 Measures and Drive-Related Risks: A Systematic Review and Meta-Analysis. Int. J. Environ. Res. Public Health 2020, 17, 5266. [CrossRef]

24. Zheng, Z.; Xiang, Q.; Gu, X.; Ma, Y.; Zheng, K. The Influence of Individual Differences on Diverging Behavior at the Weaving Sections of an Urban Expressway. Int. J. Environ. Res. Public Health 2020, 18, 25. [CrossRef]

25. Schwarzer, R. Modeling Health Behavior Change: How to Predict and Modify the Adoption and Maintenance of Health Behaviors. Appl. Psychol. 2008, 57, 1-29. [CrossRef]

26. Mace, F.C.; Critchfield, T.S. Translational research in behavior analysis: Historical traditions and imperative for the future. J. Exp. Anal. Behav. 2010, 93, 293-312. [CrossRef]

27. DíazE, M. Theory of planned behavior and pedestrians' intentions to violate traffic regulations. Transp. Res. Part F Traffic Psychol. Behav. 2002, 5, 169-175. [CrossRef] 
28. Krueger, J.I.; Funder, D.C. Towards a balanced social psychology: Causes, consequences, and cures for the problem-seeking approach to social behavior and cognition. Behav. Brain Sci. 2004, 27, 313-327. [CrossRef]

29. Petersoo, P. Reconsidering otherness: Constructing Estonian identity. Nations Natl. 2007, 13, 117-133. [CrossRef]

30. De Paola, M.; Scoppa, V.; Falcone, M. The deterrent effects of the penalty points system for driving offences: A regression discontinuity approach. Empir. Econ. 2012, 45, 965-985. [CrossRef]

31. Benedettini, S.; Nicita, A. The costs of avoiding accidents: Selective compliance and the 'Peltzman effect' in Italy. Int. Rev. Law Econ. 2012, 32, 256-270. [CrossRef]

32. Official Website of the State Road Safety Inspectorate of the Ministry of Internal Affairs of the Russian Federation. Available online: http:/ / stat.gibdd.ru/ (accessed on 18 November 2021).

33. Official Website of the Federal State Statistics Service of the Russian Federation. Available online: https:/ / rosstat.gov.ru/folder/ (accessed on 20 November 2021).

34. Pulyanova, K.V.; Voevodin, E.S.; Fadeev, A.I.; Fomin, E.V.; Askhabov, A.M.; Kashura, A.S. Analysis of road safety assessment methods. IOP Conf. Ser. Mater. Sci. Eng. 2019, 632, 012015. [CrossRef]

35. Fedoseev, S.A.; Stolbov, V.Y.; Gitman, M.B.; Pustovoyt, K.S. Improving the quality of the industrial enterprise management based on the network-centric approach. R-Economy 2015, 1, 608-617. [CrossRef]

36. Shenker, O. Information vs. entropy vs. probability. Eur. J. Philos. Sci. 2020, 10, 5. [CrossRef]

37. Buchdahl, H.A. The Concepts of Classical Thermodynamics; Cambridge University Press: Cambridge, UK, 1966; 223p.

38. Kostic, M.M. The Elusive Nature of Entropy and Its Physical Meaning. Entropy 2014, 16, 953-967. [CrossRef]

39. Ribeiro, M.; Henriques, T.; Castro, L.; Souto, A.; Antunes, L.; Costa-Santos, C.; Teixeira, A. The Entropy Universe. Entropy 2021, 23, 222. [CrossRef] [PubMed]

40. Shannon, C.E. A Mathematical Theory of Communication. Bell Syst. Tech. J. 1948, 27, 379-423. [CrossRef]

41. Petrov, A.I.; Kolesov, V.I.; Petrova, D.A. Theory and Practice of Quantitative Assessment of System Harmonicity: Case of Road Safety in Russia before and during the COVID-19 Epidemic. Mathematics 2021, 9, 2812. [CrossRef]

42. World Health Organization. Global Status Report on Road Safety 2015; World Health Organization: Geneva, Switzerland, 2015; Available online: https://www.afro.who.int/sites/default/files/2017-06/9789241565066_eng.pdf (accessed on 29 November 2021).

43. World Health Organization. Global Status Report on Road Safety 2018; World Health Organization: Geneva, Switzerland, 2018; Available online: https:/ / www.who.int/publications/i/item/9789241565684 (accessed on 29 November 2021).

44. Klinjun, N.; Kelly, M.; Praditsathaporn, C.; Petsirasan, R. Identification of Factors Affecting Road Traffic Injuries Incidence and Severity in Southern Thailand Based on Accident Investigation Reports. Sustainability 2021, 13, 12467. [CrossRef]

45. Wilde, G.J.S. The Theory of Risk Homeostasis: Implications for Safety and Health. Risk Anal. 1982, 2, 209-225. [CrossRef]

46. Blincoe, L.J.; Miller, T.R.; Zaloshnja, E.; Lawrence, B.A. The Economic and Societal Impact of Motor Vehicle Crashes, 2010; (Revised) (Report No. DOT HS 812 013); National Highway Traffic Safety Administration: Washington, DC, USA, 2015.

47. Pérez-Núñez, R.; Ávila-Burgos, L.; Híjar-Medina, M.; Pelcastre-Villafuerte, B.; Celis, A.; Salinas-Rodríguez, A. Economic impact of fatal and non-fatal road traffic injuries in Guadalajara Metropolitan Area and Jalisco, Mexico. Inj. Prev. 2011, 17, $297-303$. [CrossRef]

48. Pérez-Núñez, R.; Pelcastre-Villafuerte, B.; Hijar, M.; Ávila-Burgos, L.; Celis, A. A qualitative approach to the intangible cost of road traffic injuries. Int. J. Inj. Control. Saf. Promot. 2012, 19, 69-79. [CrossRef] [PubMed]

49. Petrov, A.; Kolesov, V. Entropic analysis of dynamics of road safety system organization in the largest Russian cities. IOP Conf. Ser. Earth Environ. Sci. 2018, 177, 012015. [CrossRef]

50. Smeed, R.J. Some Statistical Aspects of Road Safety Research. J. R. Stat. Soc. Ser. A 1949, 112, 1-34. [CrossRef]

51. Smeed, R.J. Variations in the pattern of accident rates in different countries and their causes. Traffic Eng. Control 1968, 10, 364-371.

52. Kolesov, V.; Petrov, A. Cybernetic Modeling in Tasks of Traffic Safety Management. Transp. Res. Procedia 2017, 20, 305-310. [CrossRef]

53. Road Safety Profiles of the Subjects of the Russian Federation 2020. Available online: https://xn--90aga7a7b.xn--b1aew.xn--p1ai/ dop_stranici $/ \%$ D0\%BE $\%$ D0\%B1\%D0\%B7\%D0\%BE\%D1\%80\%D1\%8B-2020 (accessed on 29 November 2021). (In Russian).

54. Official Website of the Journal for Motorists «Za Rulem». All Opinion Polls. Available online: https://www.zr.ru/polls / ?archive= true (accessed on 1 December 2021).

55. Łukasik, Z.; Kuśmińska-Fijałkowska, A.; Olszańska, S. The impact of the organisation of transport processes on the efficient use of a fleet of vehicles. Sci. J. Silesian Univ. Technol. Ser. Transp. 2021, 110, 87-95. [CrossRef]

56. Bax, C.; Leroy, P.; Hagenzieker, M. Road safety knowledge and policy: A historical institutional analysis of the Netherlands. Transp. Res. Part F: Traffic Psychol. Behav. 2014, 25, 127-136. [CrossRef]

57. Petrov, A. Road Traffic Accident Rate as an Indicator of the Quality of Life. Econ. Soc. Changes Facts Trends Forecast. 2016, 3 , 154-172. [CrossRef]

58. Velichko, A.; Heidari, H. A Method for Estimating the Entropy of Time Series Using Artificial Neural Networks. Entropy 2021, 23, 1432. [CrossRef] [PubMed] 